\title{
Enhancing the Electrocatalytic Activity of Fe Phthalocyanines for Oxygen Reduction Reaction by the Presence of Axial Ligands: Pyridine-functionalized Single-Walled Carbon Nanotubes
}

\author{
María Paz Oyarzúna, Nataly Silva ${ }^{a, b}$, Diego Cortés-Arriagada ${ }^{c}$, Juan Francisco Silva ${ }^{a}$, Ingrid \\ O. Ponce ${ }^{\mathrm{d}}$, Marcos Flores ${ }^{\mathrm{e}}$, Kaido Tammeveskif ${ }^{\mathrm{f}}$, Daniel Bélanger ${ }^{\mathrm{g}}$, Andrea Zitolo ${ }^{\mathrm{h}}$, Frédéric \\ Jaouen $^{\mathrm{i}^{*}}$ and José H. Zagal ${ }^{\mathrm{a}^{*}}$
}

aLaboratorio de Electrocatálisis, Departamento de Química de los Materiales, Facultad de Química y Biología, Universidad de Santiago de Chile, Av. Libertador Bernardo O’Higgins 3363, Estación Central, Santiago 9170124, Chile.

bacultad de Diseño, Universidad del Desarrollo. Avenida Plaza 680, Las Condes, Santiago, Chile.

'Programa Institucional de Fomento a la Investigación, Desarrollo e Innovación. Universidad Tecnológica Metropolitana. Ignacio Valdivieso 2409, P.O. Box 8940577, San Joaquín, Santiago, Chile.

${ }^{\mathrm{d}}$ Laboratorio de Electrónica Molecular, Departamento de Ciencias del Ambiente, Facultad de Química y Biología, Universidad de Santiago de Chile, Av. Libertador Bernardo O’Higgins 3363, Estación Central, Santiago 9170124, Chile.

eDepartamento de Física, FCFM, Universidad de Chile, Av. Blanco Encalada 2008, Piso 3, Santiago, Chile.

Institute of Chemistry, University of Tartu, Ravila 14a, 50411 Tartu, Estonia.

gDépartement de Chimie, Faculté des Sciences, Université du Québec à Montréal, Case Postale 8888, succursale Centreville, Montréal ( Québec) H3C 3P8 Canada.

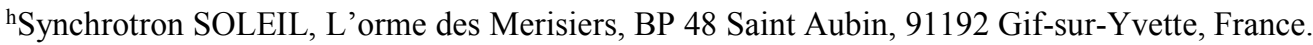

iICGM, Univ. Montpellier, CNRS, ENSCM, Montpellier, France.

\section{Abstract}

We have examined the electrocatalytic activity of iron phthalocyanine ( FePc) and perchlorinated iron phthalocyanine $16(\mathrm{Cl})$ FePor the oxygen reduction reaction ( ORR) in alkaline medium with the two molecules either adsorbed on the external surface of single-wall carbon nanotubes ( SWCNT) or covalently anchored via an axial pyridine ligand on pyridine-functionalized single-wall carbon nanotubes ( p-SWCNT) . Regardless of the particular phthalocyanine type, the ORR activity is higher when the substrate is py-SWCNT rather than SWCNT. The Tafel slopes for ORR are very similar for the two Fe macrocyclic complexes attached to SWCNTs in the two different configurations, suggesting a common rate-determining step for the ORR for all four catalysts. It is also observed 
that, for both the SWCNT and py-SWCNT supports, the ORR activity is higher for $16(\mathrm{Cl}) \mathrm{FePc}$ than for FePc. This is attributed to the electron-withdrawing effect of the peripheral and non-peripheral chlorine atoms in the macrocyclic ligand. While FeN4 macrocycles are known to be located on the strong binding side of a volcano correlation including several MN4 species, the chlorine substituents decrease the binding energy of $\mathrm{O}_{2}$ on the central Fe cation, thereby moving up the macrocycle catalyst towards the apex of the volcano correlation. Both the carbon surface and macrocyclic ligand effects were optimized with $16(\mathrm{Cl}) \mathrm{FePc}$ attached to-SyWCNT, which is more active than both FePc on SWCNT and FePc on py-SWCNT. Here we show that both the axial ligand and the electron withdrawing groups (-Cl) have a combined collaborative effect in increasing the catalytic activity for ORR of Fe-phthalocyanines confined on the external walls of single-wall carbon nanotubes.

Keywords: oxygen reduction, iron phthalocyanine, axial ligand, single-wall carbon nanotubes, electrocatalysis, redox potential.

Corresponding authors: jose.zagal@usach.cl ( J.H. Zagal), frederic.jaouen@umontpellier.fr ( F. Jaouen) .

\section{INTRODUCTION}

It is a great honor for us to the dedicate this manuscript to the memory of Professor Sergio Trasatti that combines two prominent aspects of Professor Trasatti's seminal contributions: fundamental electrocatalysis and volcano activity correlations, especially on the electrocatalytic activity of metals and metal oxides related to electrochemical energy conversion and industrial processes. Amongst metals, platinum and its alloys are the most active catalysts for the oxygen reduction reaction ( ORR) in acidic medium[1-3] and still the most often employed materials for catalyzing the ORR in the high-pH medium prevailing in the recently developed polymer electrolyte fuel cells with anion exchange membranes ( AEMs[4,5] However, due to the high cost and scarcity of platinum, many 
groups for decades have focused their research on the development of alternative catalysts based on less expensive and more abundant chemical elements, with the aim of replacing platinum at the $\mathrm{O}_{2}$ reducing cathode of both proton-exchange membrane ( PEM) and AEAdsed fuel cells.[4,5] The slow kinetics of the ORR, even on Pt, is limiting the overall efficiency and power density of lowtemperature fuel cells.[6,7,16,8-15] Studies on platinum group metal-free catalysts have concentrated on the use of various catalyst precursors and macrocyclic ligands to prepare novel catalysts with reduced cost and lower overpotential for ORR. For example, MN4 complexes such as metallophthalocyanines and metalloporphyrins have been widely investigated as molecular catalysts for ORR since the mid-1960s[17] but they lack the long-term stability, necessary for fuel cell applications, especially in acid. However, they can serve as models for establishing reactivity guidelines for ORR on metal-N $\mathrm{N}_{4}$ centers. Due to their extended electronic $\pi$-systems, such macrocyclic complexes can undergo very fast and reversible redox processes centered on the metal ion as the processes involve very low reorganization energies. Therefore, they can act as mediators in electron transfer processes involving numerous reactants.[18-25] The $\mathrm{FeN}_{4}$ macrocycles are particularly interesting because of their structural similarity with the $\mathrm{FeN}_{4}$ active site in hemoproteins, comprising important biological catalysts such as cytochromes and peroxidases as well as the $\mathrm{O}_{2}$-carrier hemoglobin.[26] Even though such unadulterated MN4 macrocycles lack long term stability in the corrosive environment of acidic fuel cells and even perhaps in AEM fuel cells, they are interesting as a structural model with clearly identified active centers. Furthermore, their intrinsic catalytic activity can be modulated by changing the chemical structure of the macrocyclic ligand by adding targeted peripheral and non-peripheral functional groups or atoms on the ligand.[27] This chemical versatility facilitates the identification of reactivity descriptors that can in turn serve as powerful guidelines for the development of more active non-precious metal catalysts more akin to solid-state chemistry, involving metal- $\mathrm{N}_{\mathrm{x}}$ moieties integrated in carbon and graphitic matrices. 
The ORR activity of metallo-porphyrins and metallo-phthalocyanines has been shown to mainly depend on two factors, namely the chemical nature of the central metal ion,[28] and the type of peripheral and non-peripheral substituents in the macrocycle.[29-35] In particular, the electronegative character of the peripheral substituent has been shown to play a key role on the turnover frequency for the ORR of the central metal cation.[36-38] Various strategies have been attempted and, when successful, developed in order to further increase the electrocatalytic activity and stability of such macrocyclic complexes. One can mention in particular efforts to improve; ( i) their adsorption on various nanocarbon supports,[39-43] ( ii) their integration in or on the carbon surface ( with partial or complete loss of the macrocycle structure) via hæałatment in an inert atmosphere,[44-50] or ( iii) their covalent bonding to the carbon surfacia an additional axial ligand, for example pyridine [51-53] and imidazole.[54] The latter strategy has allowed the tuning of the catalytic properties of $\mathrm{Fe}$ and $\mathrm{Co}$ phthalocyanines anchored via an axial ligand, modifying its M( III) /(redd $\phi x$ potential and therefore its activity towards the ORR. This effect has also been observed using other types of supports, such as gold, where the $\mathrm{FeN}_{4}$ complexes are coordinated to a self-assembled monolayer ( SAM[55-59] Heat treatment modifies the ligation around the Fe center shifting the Fe( III) II) to more positiwalues.[60]

The combined effect of an optimized FePc redox potential and optimized bonding or adsorption of various FePc's on a carbon allotrope surface has not yet been systematically investigated. Cao et al.[51] studied FePc on pyridine-functionalized SWCNT. However, FePc is known to be located far off the maximum ORR activity in the volcano plot experimentally charted for the family of iron phthalocyanines.[33] FePc's functionalized by highly electronegative ligand substituents, thereby providing a more positive $\mathrm{Fe}(\mathrm{III}) / \mathrm{Fe}(\mathrm{II})$ redox potential, have demonstrated higher intrinsic ORR activity. This is especially the case of perfluorinated phthalocyanine that seems to exhibit the highest experimental activity for ORR, appearing on the apex of the volcano correlation.[37] 
In this work, we have investigated the combined effect of the SWCNT surface and of substituent of the ligand of the Fe-phthalocyanines on the ORR activity in alkaline medium. Namely, the present study evaluated the four combinations between SWCNT or py-SWCNT as carbon supports, and the all hydrogen FePc or fully chlorinated $16(\mathrm{Cl}) \mathrm{FePc}$ as iron phthalocyanines. The incorporation of axial ligand to SWCNT leads to an increased ORR activity of the catalyst materials involving Fephthalocyanines coordinated to py-SWCNT compared to those involving the same phthalocyanines physically adsorbed on SWCNT.

\section{MATERIALS AND METHODS}

Materials and chemicals. The $\mathrm{FeN}_{4}$ complexes, iron phthalocyanine ( $\mathrm{FePc}$ ) aperchlorinated iron phthalocyanine ( $16(\mathrm{Cl})$ FePc) , ( Figure Spùrchased from Sigma Aldrich and used as received. Single-wall carbon nanotubes ( SWCNTs) EQ0 were obtained from CHASM Advanced Materials, USA with 90 wt.\% carbon purity and an average diameter of $0.87 \mathrm{~nm}$. Sodium nitrite ( NaNQ) and-4minopyridine ( Apy, purity $\geq 99 \%$ ) were obtained from Merck and Sigma Aldrich, respectively. Sodium hydroxide ( $\mathrm{NaOH}$ ) and Ndimethylformamide ( DMF) were purchased from Merck while ultrapure water used for all experiments was procured using a Milli-Q water system ( resistity of $18.2 \mathrm{M} \Omega \mathrm{cm}$, Simplicity®, Merck) .

Catalysts preparation. py-SWCNTs and FeN4-py-SWCNT composites were prepared using a procedure described by Cao et al. based on the diazonium reaction.[51] $2.5 \mathrm{~g}$ of $\mathrm{NaNO}_{2}$ was dissolved in $3.5 \mathrm{~mL}$ of water and cooled at $0{ }^{\circ} \mathrm{C}$ in an ice bath. Furthermore, $3.3 \mathrm{~g}$ of 4-aminopyridine ( 4 py) was dissolved in $2.5 \mathrm{~mL}$ of $4 \mathrm{M} \mathrm{HCl}$ and cooled at $0{ }^{\circ} \mathrm{C}$. Then the $\mathrm{NaNO}_{2}$ solution was added dropwise to the 4-APy solution and the resulting yellow solution was stirred for $30 \mathrm{~min}$ at $0{ }^{\circ} \mathrm{C}$.

$50 \mathrm{mg}$ of SWCNTs were dispersed in $100 \mathrm{~mL}$ of DMF for $2 \mathrm{~h}$ using an ultrasonic bath. This 
dispersion was then cooled at $0{ }^{\circ} \mathrm{C}$ and added dropwise to the yellow solution of 4-Apy and $\mathrm{NaNO}_{2}$ prepared and maintained in a bath at $0{ }^{\circ} \mathrm{C}$. The mixture was reacted at $0{ }^{\circ} \mathrm{C}$ for $3 \mathrm{~h}$ and then was stirred at room temperature for $15 \mathrm{~h}$. The resulting product ( pySWCNT) was collected by filtering and thoroughly washed with $2 \mathrm{M} \mathrm{HCl}, 2 \mathrm{M} \mathrm{NaOH}$, water and acetone. The py-SWCNT powder was dried overnight at $60{ }^{\circ} \mathrm{C}$ in an oven, and then stored in dry conditions. Next, the FeN 4 -py-SWCNT composite materials were prepared by mixing $98.6 \mathrm{mg}$ of py-SWCNT and $50 \mathrm{mg}$ of Fephthalocyanine $\mathrm{FePc}$ or $16(\mathrm{Cl}) \mathrm{FePc}$ in DMF by refing with constant stirring at $150{ }^{\circ} \mathrm{C}$ for $3 \mathrm{~h}$ with $\mathrm{N}_{2}$ bubbling ( to prevent the possible oxidation of F-甲hthalocyanine macrocycles) . The final product was filtered and washed with DMF until the filtrate became clear. Finally, this composite powder was dried overnight at $60^{\circ} \mathrm{C}$ in air.

The FeN4-SWCNT composite materials were prepared by mixing $1 \mathrm{mg}$ of SWCNTs, $1 \mathrm{mg}$ of Fephthalocyanines and $1 \mathrm{~mL}$ of DMF. This dispersion was sonicated for $30 \mathrm{~min}$ and subsequently left to stand for an incubation time of $24 \mathrm{~h}$. The composite was collected via filtration with DMF and dried overnight at $60^{\circ} \mathrm{C}$ in air.

Material characterization. Raman spectroscopy measurements were performed on a micro-Raman system ( Alpha 300, WITeGGmbH) on Arrandee ${ }^{\circledR}$ gold slides of $1212 \mathrm{~mm}$ at an excitation wavelength of $633 \mathrm{~nm}$, power of $5.5 \mathrm{~mW}$ and objective lens with magnification 100x. The center of the spectrum was located at $1600 \mathrm{~cm}^{-1}$ and measurements were performed by recording 50 spectra per sample with $0.5 \mathrm{~s}$ integration time. The chemical composition of catalysts was studied with Xray photoelectron spectroscopy ( XPS) using an XPSuger Perkin Elmer spectrometer model PHI1257 which includes an ultra-high vacuum chamber, a hemispheric electron energy analyzer and an X-ray source with $\mathrm{Al} \mathrm{K \alpha}$ radiation ( $1486.6 \mathrm{eV}$ ) . Power $200 \mathrm{~W}$ and emission angle ${ }^{\circ} .7 \mathrm{He} \mathrm{K}$-edge X-ray absorption spectra of FePc and 16( Cl) FePc on SWCNT or-SyWCNT were collected at room 
temperature and in transmission mode at the SAMBA beamline of the Synchrotron SOLEIL.[61] The beamline was equipped with a sagittaly focusing Si 220 monochromator and two Pd-coated collimating/focusing mirrors; mirrors have been used to remove X-rays harmonics. The catalysts were pelletized as disks of $10 \mathrm{~mm}$ diameter with $1 \mathrm{~mm}$ thickness using cellulose powder as a binder.

Electrochemical studies. Cyclic voltammetry ( CV) and linear sweep voltammetr(y LSV) experiments were carried with a Bas-i-Epsilon electrochemical workstation using a conventional three-electrode system. The edge plane orientation of ordinary pyrolytic graphite ( OPG) , Pine Instruments, geometric area $0.196 \mathrm{~cm}^{2}$ ) was used as a working rotating disk electrode ( RDE) . Prior to use, the OPG disk was polished with 800 grit $\mathrm{SiC}$ paper followed by 1200 and 2400 grit in sequence, and finally sonicated in deionized water for $5 \mathrm{~min}$. $\mathrm{An} \mathrm{Ag} / \mathrm{AgCl}(3 \mathrm{M} \mathrm{KCl})$ electrode and a graphite bar were used as reference and counter electrodes, respectively. To prepare the working electrode, $1 \mathrm{mg}$ of composite material was dispersed in $1 \mathrm{~mL}$ of DMF and sonicated for $30 \mathrm{~min}$. Then, a $10 \mu \mathrm{L}$ aliquot of this ink dispersion was deposited on the surface of the OPG electrode, resulting in a catalyst loading of $c a 50 \mu \mathrm{g} \mathrm{cm}^{-2}$. Cyclic voltammetry was used to determine formal potentials and surface concentrations of $\mathrm{FePc}$ and $16(\mathrm{Cl}) \mathrm{FePc}$ on the different substratesVs were recorded between -1.0 and $0.2 \mathrm{~V}$ vs. $\mathrm{Ag} / \mathrm{AgCl}(3 \mathrm{M} \mathrm{KCl})$ at a scan rate of $100 \mathrm{mV}$ is a $\mathrm{N}_{2}$-saturated 0.1 M NaOH solution. The surface concentration $(\Gamma)$ of FePc and $16(\mathrm{Cl}) \mathrm{FePc}$ of the different hybrid systems ( SWCNT or pyWCNT) on the electrode was estimated from the electrical charge Q) obtained from the charge integration under the $\mathrm{CV}$ peaks attributed to the $\mathrm{Fe}(\mathrm{III}) /($ rellox process and subtracting the background capacitive current using equation: $\Gamma=\frac{Q}{n F A}$ where, $n$ is the number of transferred electrons $(\mathrm{n}=1$ in our case $) F$, the Faraday constant $\left(9,485 \mathrm{C} \mathrm{mol}^{-1}\right)$ and 4 is the geometric area of the OPG electrode ( $\left.0.196 \mathrm{chin}^{2}\right)$. 
LSVs were performed to measure the ORR activity in an $\mathrm{O}_{2}$-saturated $0.1 \mathrm{M} \mathrm{NaOH}$ solution at a scan rate of $5 \mathrm{mV} \mathrm{s}^{-1}$ with the electrode rotating at $1600 \mathrm{rpm}$. The percentage yield of $\mathrm{H}_{2} \mathrm{O}_{2}$ generated during the ORR was measured using a rotating ring-disk electrode ( RRDE) setup with a GC disk and a Pt ring ( Pine Instruments) . The potential of the Pt ring was held at $0.277 \mathrm{~V} \mathrm{Asg} / \mathrm{AgCl}$ to ensure that all peroxide reaching the Pt ring was oxidized. The collection efficiency of the ring electrode in the presence of a catalytic film on the disk was $0.33 \pm 0.01$ ( 0.37 indicated by manufacturer) .

Computational Methods. Density Functional Theory ( DFT) calculations weqerformed in the ORCA 4.1.2 program[62,63] with the PBE functional[64] and in combination with the all-electron double zeta def2-SVP basis sets for all the atoms. PBE was selected due to its implementation in studies related to FePc complexes.[58,65,66] Empirical dispersion corrections for SCF energies were implemented by the DFT-D3 method and including the Becke-Johnson damping function[67,68] to avoid interatomic repulsive terms at short distances. Calculations involving open-shell systems were developed with the unrestricted UPBE-D3 scheme; mixture with higher spin states ( spin contamination) was negligible in all the cases. All the systems were fully optimized without geometry or symmetry constraints. Adsorption energies $\left(E_{\mathrm{ads}}\right)$ were computed a $E_{\mathrm{ads}}=E_{\mathrm{A}}+E_{\mathrm{B}}-E_{\mathrm{AB}}$, where $E_{\mathrm{A}}, E_{\mathrm{B}}$, and $E_{\mathrm{AB}}$ are the total energies of the A, B fragments and A-B adduct, respectively. In this scheme, the more positive the $E_{\text {ads }}$ values, the more stable the A-B adduct is. The standard counterpoise correction by Boys and Bernardi was implemented to avoid basis set superposition errors[69] ( BSSE) in the $e_{d s}$ values. The contribution of dispersion forces to $E_{\text {ads }}\left(E_{\mathrm{vdW}}\right)$ is obtained as $E_{\mathrm{vdW}}=E_{\mathrm{disp}(\mathrm{AB})} E_{\mathrm{disp}\left({ }_{\mathrm{A}}\right)} E_{\mathrm{disp}(\mathrm{B})}$ where $E_{\mathrm{disp}(\mathrm{AB})} E_{\mathrm{disp}(\mathrm{A}) \text { and }} E_{\mathrm{disp}(\text { Bare }}$ the DFT-D3 dispersion corrections of the A-B adduct and the isolated fragments ( A and B), respectiveThe intermolecular electrostatic energies $\left(E_{\mathrm{els}}\right)$ between $\mathrm{A}$ and $\mathrm{B}$ fragments of the $\mathrm{A}-\mathrm{B}$ adducts were obtained according to the classic Coulomb energy as: 


$$
E_{e l s}=\sum_{a \in \text { frag } A} \sum_{B \in \text { frag } B} \frac{q_{a} q_{b}}{\left|R_{a}-R_{b}\right|}
$$

where $q_{\mathrm{a}}$ and $q_{\mathrm{b}}$ are the atomic charges on the atoms $a$ and $b$ of fragments A and B respectively; $R_{\mathrm{a}}-R_{\mathrm{b}}$ is the distance between atoms $a$ and $b$. The more negative the $E_{\text {els }}$ value, higher the stabilizing electrostatic interaction is; positive values indicate a repulsive interaction. The chemical nature of the bonding in the FePc-SWCNT adducts was also studied by the Atoms-in-Molecules ( AIM) technique. AIM quantifies the electron density $\left(\rho_{\mathrm{i}}\right)$ at the bond critical points ( BCPs) of inter and intramolecular interactions and connected by bond paths.[70] Covalent bonds, coordinate covalent bonds ( highly polarized closedhell interactions), and weak electrostatic interactions are commonly characterized in the AIM analysis by $\rho_{\text {i }}$ values in the range of $\sim 0.5-0.2,0.10-0.04$ and $\leq 0.01 e / \mathrm{Bohr}^{3}$ at its BCPs, respectively.[70] Mulliken charges, AIM analyses, and wavefunction analyses were performed in the Multiwfn 3.6[71] code.

\section{RESULTS AND DISCUSSION}

\subsection{Characterization of SWCNT and py-SWCNT}

XPS spectra were acquired on the commercial carbon nanotubes in order to rule out the presence of metallic Fe particles that might come from their synthesis. A survey spectrum recorded for binding energies ranging from 0 to $800 \mathrm{eV}$ ( ifgure S2) shows the signals of carbon ( $\mathrm{C} 1 \mathrm{~s}$ ) and oxygen ( $\mathrm{O} 1 \mathrm{~s}$ ) from carbonyl $(\mathrm{C}=\mathrm{O})$ and carbox $y \mathbb{C O O H}$ ) groups present on the surface o\$WCNTs. From the insert of Figure S2, the high-resolution spectrum acquired in the Fe2p region does not show any signal, demonstrating that either the synthesis of SWCNTs did not present Fe-based catalysts, or the Fe-based catalysts were successfully removed after the synthesis. 
The incorporation of functional groups composed of light elements (e.g. $\mathrm{N}, \mathrm{O}$ and $\mathrm{S}$ ) in or on SWCNTs can introduce additional functionalities that can promote electrocatalysis for a particular application and perhaps more important, can decrease the strong van der Waals interactions existing between unadulterated SWCNT, thus leading to their aggregation needed.

The functionalization of SWCNT by pyridine molecules was then first verified by XPS ( Figure S3) . The N1s core level spectrum for SWCNTs-py shows a single peak at $398.7 \mathrm{eV}$, corresponding to the binding energy of pyridinic $\mathrm{N}$ and suggests that the pyridyl groups were successfully anchored on the carbon nanotubes. Due to a single layer of carbon in SWCNTs, the surface composition provided by XPS can in this case be also assumed to represent the bulk composition ( the penetration depth of XPS in carbon materials is several $\mathrm{nm}$ ) . The N speciation in pySWCNT is shown to be exclusively pyridinic nitrogen, as expected. We also investigated py-SWCNT with Raman spectroscopy. Raman spectroscopy is a powerful tool for the characterization of carbon materials in general and of SWCNT in particular. In the case of SWCNT, it has been reported that Raman spectroscopy can monitor the chemical and/or electronic changes upon surface functionalization.

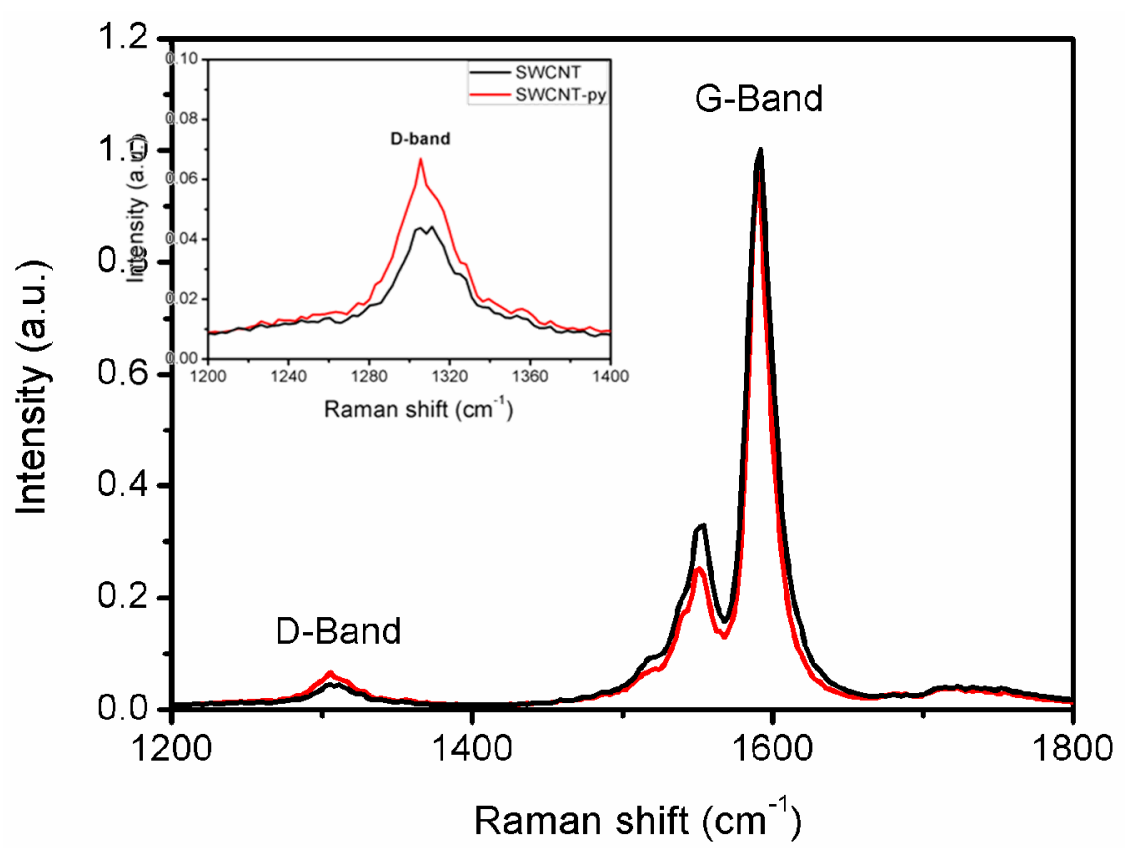


Figure 1. Raman spectra of SWCNT ( black curve) and-pyWCNT ( red curve) recorded with a 633 $\mathrm{nm}$ excitation wavelength. The spectra were normalized to the intensity of the G-band at $1592 \mathrm{~cm}^{-1}$.

Figure 1 shows the Raman spectra for SWCNT ( solid black curve) and-\$yWCNT ( solid red curve) , both showing the well-known D and G bands. The D-band commonly observed between 1300 and $1400 \mathrm{~cm}^{-1}$ for all carbon materials, is called the defect-band.[72] For SWCNT with identical length and diameter, the relative intensity gives an approximate degree of functionalization.[72],[73] It is here verified that the Raman spectrum of py-SWCNT shows a significant increase in the relative intensity of the D-band at $1305 \mathrm{~cm}^{-1}$ compared to SWCNT ( inset of Figure 1) , with had $I_{\mathrm{G}}$ ratio of 0.066 for py-SWCNT versus 0.043 for SWCNT. This indicates that the pyridine molecules are covalently bonded to the carbon nanotubes external wall, via the conversion of some $\mathrm{sp}^{2}$ carbon atoms on the surface of SWCNT into $\mathrm{sp}^{3}$ carbon atoms in py-SWCNT.[74]

\subsection{Surface characterization of $\mathrm{FeN}_{4}-\mathrm{py}-\mathrm{SWCNT}$ catalysts}

The electronic structure of Fe for the commercial Fe-phthalocyanines and hybrid materials was investigated by XPS. The Fe2p core level spectra of Figures $2(\mathrm{~A})$ and $(\mathrm{B})$ klecpresence of Fe ion in the oxidized state Fe( III) , but also somethe Fe( II) stater ex situ FePc-py-SWCNT and 16( $\mathrm{Cl})$ FeBy-SWCNT. The Fe2p high-resolution spectra shows two regions around 710 and 723 $\mathrm{eV}$, due to spin-orbit coupling leading to a splitting of the $2 \mathrm{p}_{3 / 2}$ and $2 \mathrm{p}_{1 / 2}$ transitions, respectively.[42] The fitting components at 710 and $723 \mathrm{eV}$ are assigned to $\mathrm{Fe}^{2+}$ while the contributions at 712 and $725 \mathrm{eV}$ are assigned to $\mathrm{Fe}^{3+}$.[75] Both spectra necessitate a third component at ca $714 \mathrm{eV}$ corresponding to the binding energy of the $\mathrm{Fe}^{2+}$ satellite $2 \mathrm{p}_{1 / 2 .}[76]$ In the $\mathrm{Fe} 2 \mathrm{p}_{3 / 2}$ core level spectra in both FePc-py-SWCNT and 16( $\mathrm{Cl})$ FeBy-SWCNT, a shift to higher binding energy from 710 to $711.1 \mathrm{eV}$ and an increment of the intensity of the $\mathrm{Fe}^{3+}$ component is observed compared to FePcSWCNTs and 16( $\mathrm{Cl})$ FePc. This displacement is compatible with a decrease in the electron density around the iron atom in the phthalocyanine structure, attributed to the presence of the axial ligand 
pyridine that generates a displacement of the population of electrons in the iron atom and in addition to the presence of the chlorine atoms on the ligand in $16(\mathrm{Cl}) \mathrm{FePc}$, which is in agreement with previous studies $[51,52,77]$ and with voltammetric data (vide infra) .
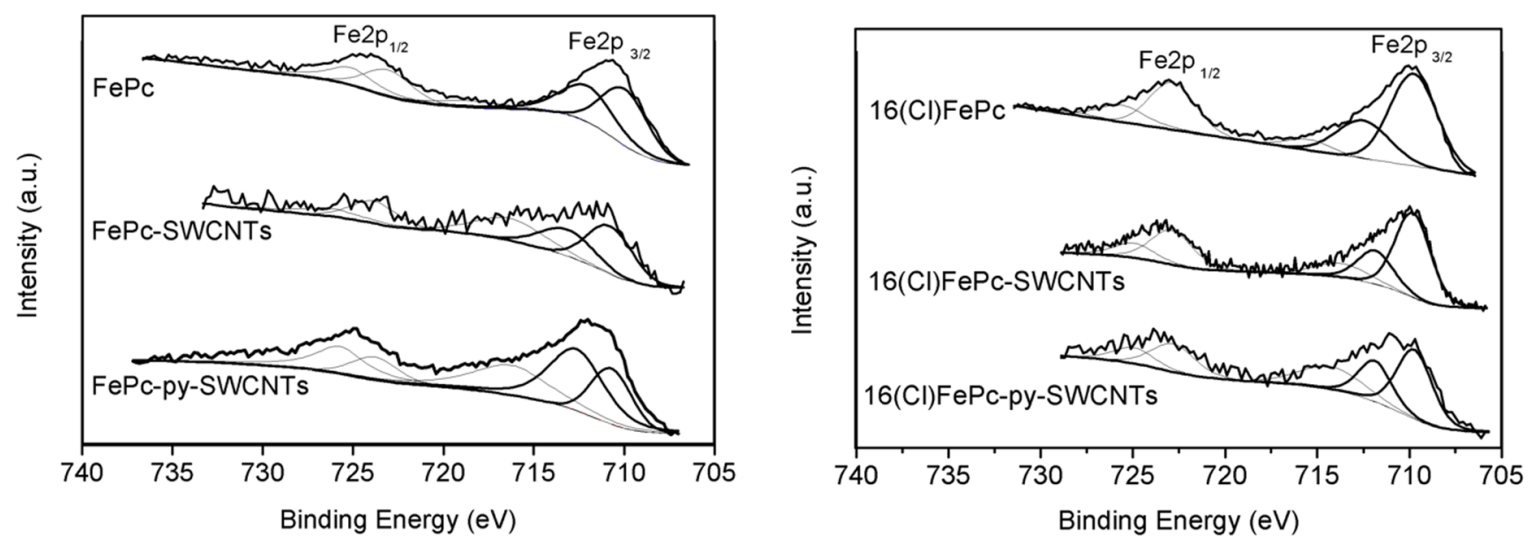

Figure 2. XPS Fe2p spectra of ( A) FePc, FeBdCNTs and FePc-py-SWCNTs samples. ( B) 16( $\mathrm{Cl}) \mathrm{FePc}, 16(\mathrm{Cl})$-SHdRCNTs and 16( Cl) Fepy-SWCNTs samples.

The fitting of the N1s XPS spectra for the two py-functionalized SWCNT samples ( Figure S4) shows two well-defined fitting components, with binding energy at around 399.2 and $401.2 \mathrm{eV}$ assigned to meso and metal-ligating pyrrole ( $\mathrm{F}-\mathrm{Nx}$ ) from the phthalocyaimes, respectively, and graphitic nitrogen of the structure of phthalocyanine.[42,78], When the phthalocyanine is adsorbed on the external surface of SWCNTs[42,79] the same contributions are observed, with a slight increase in the intensity of the ratio of graphitic-nitrogen/metal-ligating $\mathrm{N}$, attributed to the presence of nanotubes. Finally, the FePc-py-SWCNT and 16( Cl) Fepy-SWCNT samples show a third component at $397.2 \mathrm{eV}$, corresponding to pyridine nitrogen[80] and a fourth pyridine oxide ( 403.8 eV).[42,79] This suggests that the pyridine ligand exists when it is coordinated to the Fe center of the phthalocyanine. 
In order to more precisely determine the coordination geometry around $\mathrm{Fe}$ ions in $16(\mathrm{Cl}) \mathrm{FePc}$ SWCNTs and 16( Cl) FeBy-SWCNTs, X-ray Absorption Near-Edge Structure ( XANES) spectra were acquired.

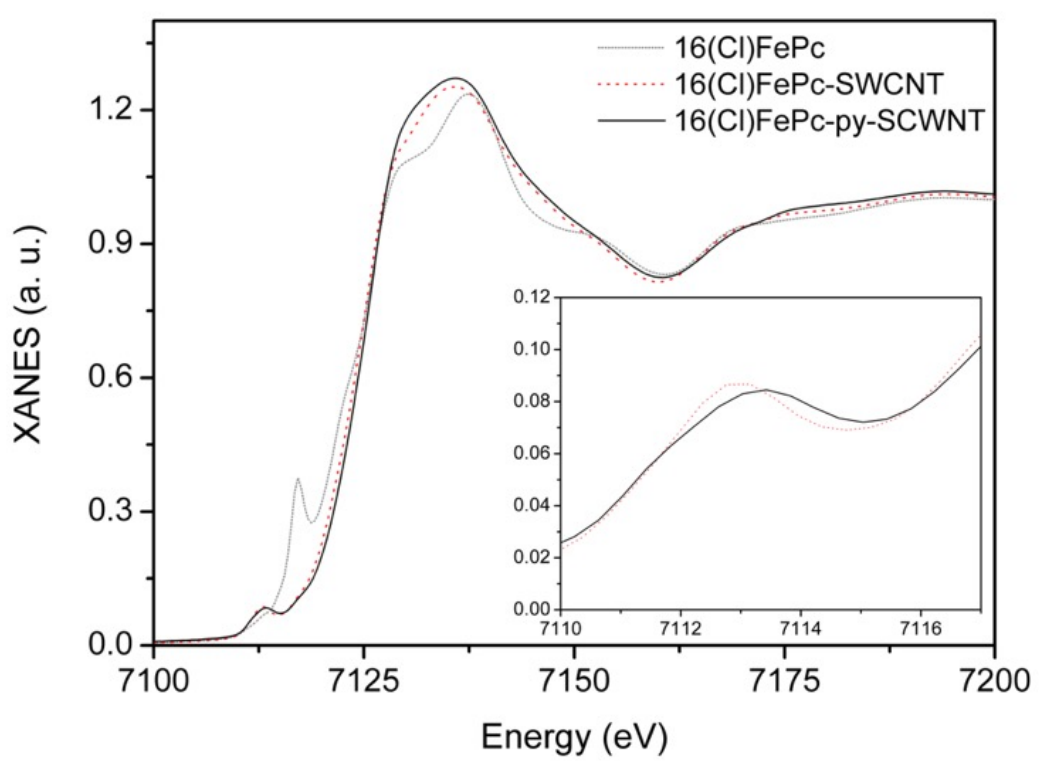

Figure 3. Comparison between the Fe K-edge XANES experimental spectra of $16(\mathrm{Cl}) \mathrm{FePc}(-$ dot gray curve) , 16( $\mathrm{Cl}$ ) F\$RCNT ( deted curve) and6( $\mathrm{Cl})$ Fepy-SWCNTs ( solid black curve) .

The XANES spectrum of $16(\mathrm{Cl})$ FePc shows some differences in the edge region up to $7152 \mathrm{eV}$. These differences are due to a different stacking arrangement of the phthalocyanine rings in the crystal structure of $16(\mathrm{Q} / \mathrm{FePc}$, where $-\pi \pi$ stacking interactions are distinctive features of this compound, without any modification of the macrocycle geometry.[81] Another spectral signature is the intense pre-edge peak at $7118.0 \mathrm{eV}$, that has been assigned to a $1 \mathrm{~s} \rightarrow 4 \mathrm{p}_{\mathrm{z}}$ shakedown transition, characteristic of square-planar configurations with high $\mathrm{D}_{4 \mathrm{~h}}$ symmetry.[82,83] In contrast, the XANES spectra of $16(\mathrm{Cl})$ FeBdVNT and $16(\mathrm{Cl})$ FeBy-SWCNT show no pre-edge peak at $7118.0 \mathrm{eV}$, but a pre-edge peak at approximately $7114 \mathrm{eV}$ ( not seen for6( $\mathrm{Cl}) \mathrm{FePc}$ ), assigned to a dipole-forbidden but quadrupole-allowed $1 \mathrm{~s} \rightarrow 3 \mathrm{~d}$ transition, typical for square-pyramidal Fe( III) complexes.[84] The presence of this pre-edge peak for 16( $\mathrm{Cl})$ FeBdCNT and 16( $\mathrm{Cl}) \mathrm{FeBy}$ SWCNT may be caused by some impurity atoms ( such as oxygen atoms) between the phthalocyanine 
structure and the SWCNTs [42] or due to the fact that part of the phthalocyanine was oxidized to form $\mu$-oxo derivatives, having a square-pyramidal symmetry, because it is known that the iron phthalocyanines easily oxidized in the presence of air.[83]

\subsection{Computational studies}

DFT studies were performed to get a detailed picture of the surface characterization of the FeN4SWCNT and FeN4-py-SWCNT catalysts. Figure 4 shows the most stable interaction modes of the formed adducts and Table I displays their properties. In all the calculations, an armchair $(6,6)$ SWCNT ( diameter $8.2 \AA$ ) was implemented as representative of the experimentally used SWCNT, this is according to the conductor character and average diameter ( $8.7 \AA)$.

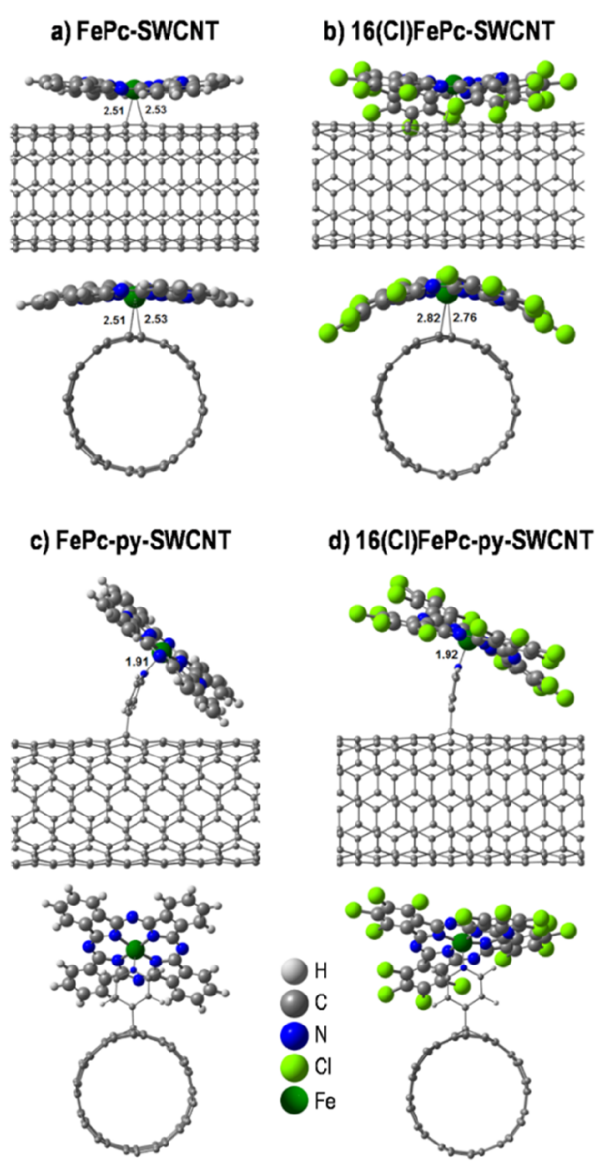

Fig.4. Optimized molecular structures of FePc and16( Cl) FePc on SWCNT and-\$ylWCNT. 
Table I. Properties of FePc and 16( $\mathrm{Cl}) \mathrm{FePc}$ on SWCNT and-pyWCNT: Adsorption energy $\left(E_{\mathrm{ads}}\right)$, dispersion energy $\left(E_{\mathrm{vdW}}\right)$, electrostatic interaction energyE $\left.E_{\mathrm{els}}\right)$, charge of SWCNTQ $\left.{ }_{\mathrm{sWCNT}}\right)$, charge of Fe atom $\left(Q_{\mathrm{Fe}}\right)$, charge of phthalocyanine (

Energies are in $\mathrm{eV}$, and charges are in $|e|$.

\begin{tabular}{lcccccc}
\hline \multicolumn{1}{c}{ System } & $E_{\mathrm{ads}}$ & $E_{\mathrm{vdW}}$ & $E_{\mathrm{els}}$ & $Q_{\text {SWCNT }}$ & $Q_{\mathrm{Fe}}$ & $Q_{\mathrm{Pc}}$ \\
\hline FePc-SWCNT & 0.53 & 2.03 & -0.11 & 0.15 & 0.54 & -0.69 \\
16( Cl) FeBdCNT & 1.28 & 3.18 & -0.32 & 0.39 & 0.58 & -0.97 \\
FePc-py-SWCNT & 1.18 & 0.90 & -0.25 & 0.25 & 0.54 & -0.79 \\
16( Cl $)$ FeBy-SWCNT & 1.40 & 0.82 & -0.28 & 0.29 & 0.53 & -0.82 \\
\hline
\end{tabular}

The interaction of FePc and $16(\mathrm{Cl})$ FeRath a pristine surface of SWCNT is characterized by adsorption energies of 0.53 and $1.28 \mathrm{eV}$, respectively, indicating that the adsorption of metal phthalocyanines is stable on SWCNTs of relative diameter $\sim 8.2 \AA$. Interestingly, the diameter of the nanotube is small enough to allow the [2+1]-cyclo-addition binding mode between the Fe atom of the complexes and one $\mathrm{C}-\mathrm{C}$ bond in the SWCNT ( $2 \mathrm{C}$ atoms $+1 \mathrm{Fe}$ atom)where the intermolecular Fe-C distances in the $16(\mathrm{Cl})$ FePc-SWCNT system are higher2(8 $\AA)$ comparedo those in the FePc-SWCNT system $(\sim 2.5 \AA)$ ( Firgs 4a-b) . Although the [2+1£ycloaddition is expected to give higher stability for these adducts, the short intermolecular distances between aromatic systems are expected to rise destabilizing contributions due to volume-exclusion effects when two fragments are compressed ( Pauli repulsion)which are also responsible by the differences in intermolecular distances. In other words, the electronic part of the interaction is repulsive, and the adsorption energies are mainly favored by the contribution of stabilizing long-range interactions. In this regard, the contribution of dispersion forces $\left(E_{\mathrm{vdW}}\right.$, Table I) is higher in both cases, contributing up to 3.18 $\mathrm{eV}$ to the adsorption energy. The high stability of the $16(\mathrm{Cl})$ FePSCNT system compared to FePc-SWCNT is also explained by a larger contribution of dispersion forces in the former, which 
agree with the concave structure of $16(\mathrm{Cl}) \mathrm{FePc}$ on SWCNT (uneifb) In addition, phthalocyanines are highly electrophilic compounds; so their interaction with SWCNT induces electron transfer in the SWCNTS $\rightarrow$ FePc direction as noted in Table I. The SWCNT charge after interaction $\left(Q_{\text {SWCNT }}\right)$ is of the order of $0.2-0.4|e|$. The higher electronegativity of $\mathrm{Cl}$ relative to $\mathrm{H}(2.8(\mathrm{Cl}), 2.2(\mathrm{H})$, in the Pauling scale) increases the electron transfer from SWCNTo $16(\mathrm{Cl})$ FeBWCNT compared to that observed for FePc on SWCNT ( 0.39 vs 0.15 ) , and also for 16( $\mathrm{Cl}$ )-pFyeBdCNT compared to FePc-py-SWCNT ( 0.29 vs 0.25 ) . The higheracge transfer from SWCNT or py-SWCNT towards $16(\mathrm{Cl}) \mathrm{FePc}$ leads to a higher stability of the $16(\mathrm{Cl})-\mathrm{FeBg}$ SWCNT systems as revealed by the lower energies of the later. This stability is not related to its stability as a catalyst under operating conditions. The electrostatic interaction energies $\left(E_{\mathrm{els}}\right)$ are attractive in both systems, but more stabilizing for the $16(\mathrm{Cl})$ FePSWCNT system as noted in Table I. In the case of py-SWCNT, the interactions between FePc or $16(\mathrm{Cl}) \mathrm{FePc}$ and-sylWCNT are modified by the presence of the $\mathrm{N}-\mathrm{Fe}$ bonding of $\sim 1.9 \AA$ in length. This results in higher adsorption energies, especially for the FePc case ( 1.18 vs 0.53 ) compared to $16 \mathrm{ClFePC}$ ( 1.40 and lą8) with adsorption energies of 1.2-1.4 eV, indicating that the interaction involve chemical ( chemisorption)as suggested from XPS measurements. As expected, the contribution of dispersion forces decreases due to the major role of the $\mathrm{N}-\mathrm{Fe}$ interaction. Note that from the theoretical calculations, $\mathrm{FePc}$ and $16(\mathrm{Cl}) \mathrm{FePc}$ display a tilted position when placed on py-SWCNT; in this way, dispersion and electrostatic stabilizing contributions increase the stability of the formed adducts. Finally, the order of stability among all the adducts varies as $16(\mathrm{Cl})$ FeBy-SWCNT $>$ FePc-py-SWCNT $>16(\mathrm{Cl})$ FeBWCNT $>$ FePcSWCNT. Wavefunction analyses were also performed to give additional insights into the role of the [2+1]-cycloaddition between FePc and 16( $\mathrm{Cl})$ FePc with intrinsic SWCNT ( Figure 5) . In the case of the FePc-SWCNT adduct ( Figure 5a) , the AIM analysiggests that the electron density $\left(\rho_{i}\right)$ at the $\mathrm{BCP}$ of the $\mathrm{Fe}-\mathrm{C}$ bonds is similar in magnitude to that of the covalent $\mathrm{C}-\mathrm{C}$ bond in the SWCNT 
$\left(\rho_{i} \approx 0.28 \mathrm{e} / \mathrm{Bohr}^{3}\right)$. The FeC bonds then show a mainly covalent character with weak bond polarization. The latter is explained by the accumulation of electron density in the C-Fe-C threecenter bond as noted from the map of electron density difference after the interaction ( red solid lines at the right of Figure 5a). Therefore, the relative lowest stability of the FeP-SWCNT adduct is explained by the volume-exclusion effects due to the short intermolecular distances caused by the $[2+1]$-cycloaddition. Conversely, the $16(\mathrm{Cl})$ ePe-SWCNT adduct shows $\rho_{i}$ values at the BCPs of the $\mathrm{Fe}-\mathrm{C}$ bonds of the order of $0.02 e / \mathrm{Bohr}^{3}$ ( Fig. 2b) , indicating that the $¥(\mathrm{e}$ bonds have a highly polarized character as expected in closed-shell interactions ( coordinate covalent bond) . Unlike the case of FePc-SWCNT, there is no major accumulation of electron density in the C-Fe-C three-center bond of the16( $\mathrm{Cl}$ ) FeBWCNT adduct ( Figure 5b), which is explained by the higher acceptor properties of the $16(\mathrm{Cl}) \mathrm{FePc}$ ligand. The latter causes an increase in thecirmolecular distances in the site of interaction, and in consequence, decreasing the volume-exclusion effects and increasing the magnitude of the stabilizing terms due to long-range interactions. Similarly, the chemical nature of the Fe-N bond formed by the interaction of FePc and 16( $\mathrm{Cl}) \mathrm{FePc}$ on-SylWCNT is determined by differences in the electron-withdrawing character of the complex. Hence, the $\mathrm{Fe}-\mathrm{N}$ bond on the FePc-py-SWCNT system is mainly covalent with a weak polarization $\left(\rho_{i} \approx 0.27 \mathrm{e} / \mathrm{Bohr}^{3}\right)$ due to accumulation of electron density in the bonding region while the $\mathrm{Fe}-\mathrm{N}$ bond on the $16(\mathrm{CF}) \mathrm{Pc}-\mathrm{py}-$ SWCNT system is relatively highly polarized $\left(\rho_{i} \approx 0.11 e / \mathrm{Bohr}^{3}\right)$ due to the high electrorwithdrawing character of the $16(\mathrm{CF}) \mathrm{ePc}$ complex. Therefore, the square pyramidal symmetry of the coordination environment of $\mathrm{Fe}$ ( as suggested from XANES experiments) is a result of the threenter bond $([2+1]$-cycloaddition) of the complexes onto intrinsic SWCNT, and due to the intermolecular FeN bond by interaction onto py-SWCNT. Even in all the cases, DFT computations show that the Fe atom protrudes from the phthalocyanine plane by up to $\sim 0.2 \AA$, indicating the key role of the intermolecular interactions on the coordination environment of $\mathrm{Fe}(\mathrm{II})$. 

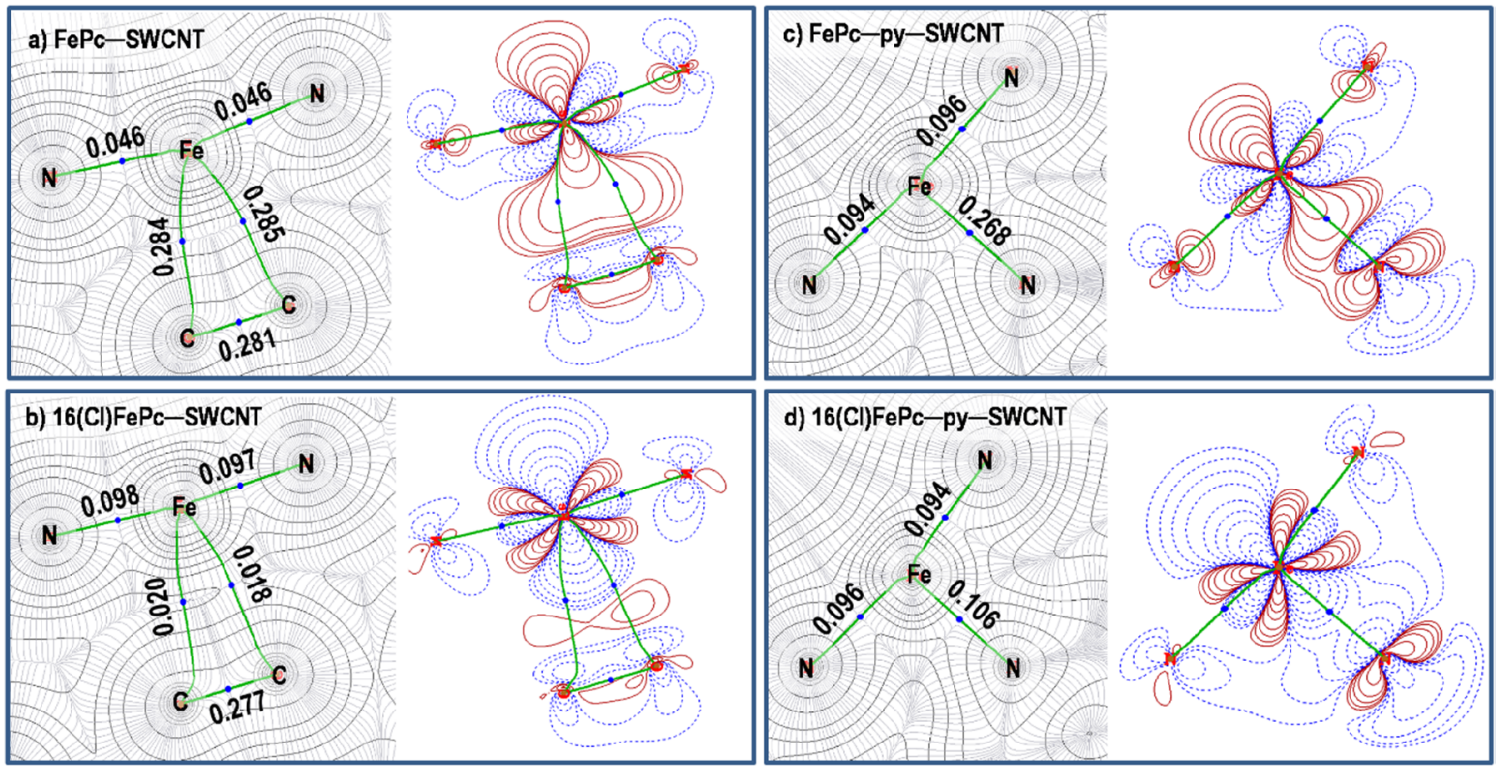

Figure 5. Each inset shows i) the gradient+contour map with topology paths of electron density along with the electron density values at bond critical points ( left) , and ii) map of electron density difference after interaction ( right), where the regions having an increased electrotensity and decreased electron density during formation of the adducts are depicted by red solid lines and blue dashed lines, respectively.

\subsection{Electrochemical evaluation of catalysts for ORR}

Iron( II) phthalocyanines exhibit wdllfined and characteristic redox processes centered on the ligand and on metal center.[22] Those redox process centered on the metal are related to the catalytic activity. Figure 6A shows cyclic voltammograms of bare OPG and OPG coated with SWCNT and py-SWCNT, measured in $\mathrm{N}_{2}$-saturated $0.1 \mathrm{M} \mathrm{NaOH}$ solution. All CVs of these Fe-free electrodes present a pure capacitive response, without redox peaks in the potential region expected for the $\mathrm{Fe}(\mathrm{III}) /(\mathrm{II})$ redox system, indicating that the electrodes are rather inert in the electrolyte solution used and in the potential range studied. Some weak signals around ca. $0 \mathrm{~V}$ can be attributed to some functionalities present on the carbon materials. In the case of OPG coated with SCWNTs and pySWCNTs, the CV curves have a greater capacitive current compared to that of bare OPG, attributed to an increase in the carbon nanotube's surface area in contact with the electrolyte.[85] Additionally, OPG modified with SWCNT and py-SWCNT shows weak redox signals at ca. $0 \mathrm{~V}$, attributed to the 
functional groups generated after the partial oxidation of the carbon nanotubes for its functionalization (e.g. carbonyl, carboxylic acids and ketones).

Figure 6B shows cyclic voltammograms for FePc and 16( $\mathrm{Cl})$ FePc coated on OPG, and also for the four materials resulting from the combination of either SWCNTs or py-SWCNT support and FePc and $16(\mathrm{Cl}) \mathrm{FePc}$, measured in-sturated $0.1 \mathrm{M} \mathrm{NaOH}$ solution. In all systems, the presence of two distinct redox processes are observed and attributed to the $\mathrm{Fe}(\mathrm{II}) /(\mathrm{I})$ and $\mathrm{Fe}(\mathrm{III}) /($ II) reversible transitions.[24],[86] Both $\mathrm{Fe}(\mathrm{II}) /(\mathrm{I})$ and $\mathrm{Fe}(\mathrm{III}) /($ II) formadf plofedntiats related to the electrocatalytic activity for several electrochemical reactions[23-25,28,34,36-39] and it can be used as reactivity descriptors. In our case, the $\mathrm{Fe}(\mathrm{III}) /(\mathrm{II})$ redox potential ( highlighted in Figure 6B is the reactivity descriptor for ORR. It has been found that the potential of this redox system correlates well with the onset of the ORR, and therefore the more positive the Fe( III) /( II) redox potential, the higher the activity.[24,87] It is interesting to note that for all catalysts the $\mathrm{Fe}(\mathrm{II}) /(\mathrm{I})$ and $\mathrm{Fe}(\mathrm{III}) /($ II) voltammetric response is rather reversible for the potential scan rate used, considering that the phthalocyanines show slightly curved structures. This curvature might diminish the aromaticity of the whole phthalocyanine structure but this effect is not noticed in the redox response. For the $\mathrm{Fe}(\mathrm{III}) /($ II) redox processes in cyclic voltammograms presented in Figure 6B, 16( E)PGbRs a more positive redox potential compared with FePc-OPG ( Table II). This is due to the electron withdrawing effect of the $-\mathrm{Cl}$ atoms, distributed in all positions in the phthalocyanine ligand.

The shift of the Fe redox couple to more positive values also increases with the incorporation of carbon nanotubes that provides a greater area for adsorption of iron complexes and therefore a greater density of catalytic active sites. The shift in the redox potential by the electron withdrawing effect of groups is a result of the stabilization of the frontier orbital associated to the Fe center and stabilizing the Fe( I) state. It is well known that Fe( III) is not active, especially in alkaline media since it 
strongly coordinates $\mathrm{OH}^{-}$anions from the electrolyte so the metal sites become occupied. Similar results are observed when the Fe metal center is coordinated to a pyridine moiety and an additional electron-pulling effect from the pyridine linker occurs.[52,53,55-58]
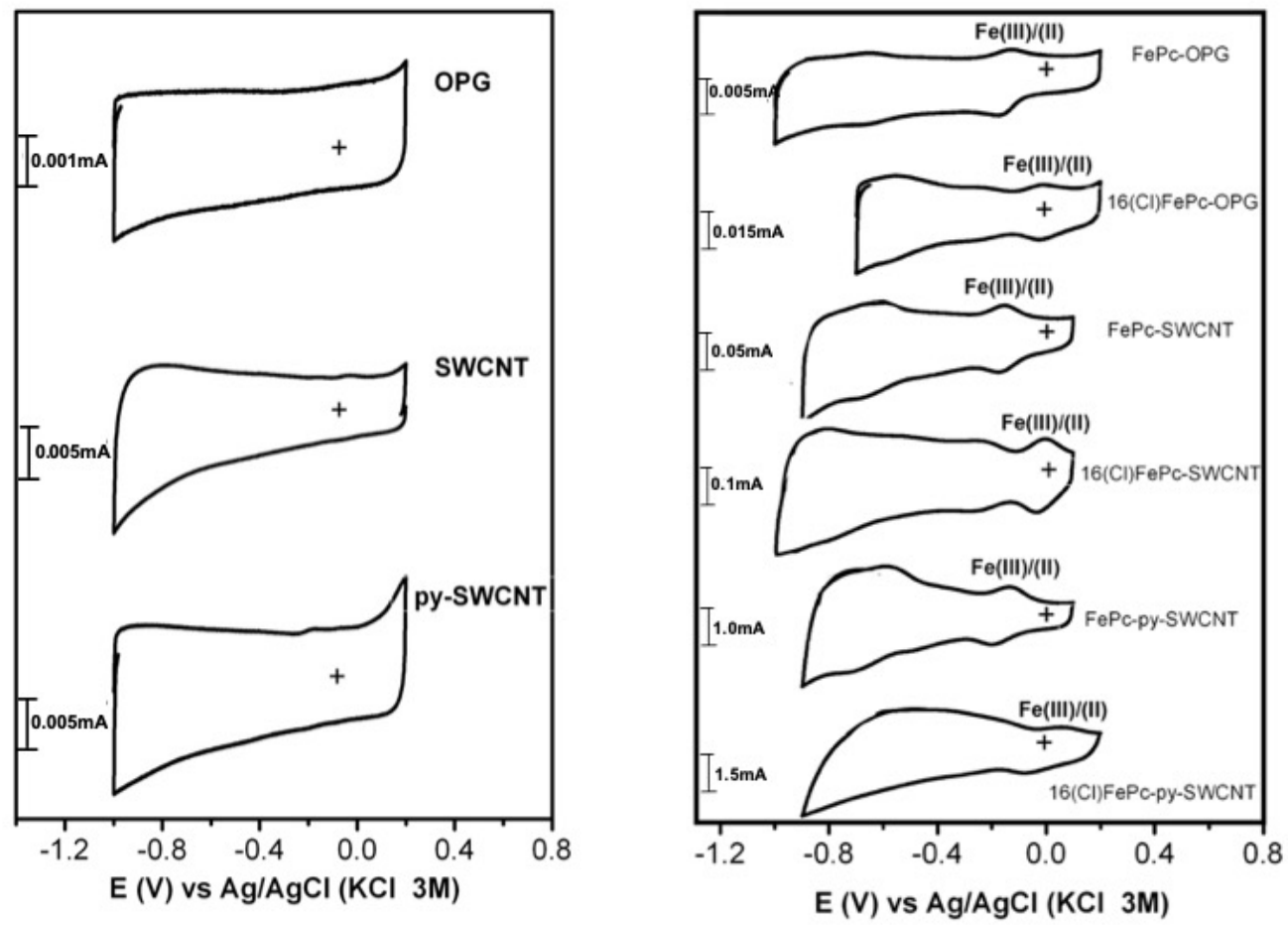

Figure 6. A. Cyclic voltammograms of OPG and modified OPG electrode with SWCNT and pySWCNT. B. Cyclic voltammograms of FePc and $16(\mathrm{Cl}) \mathrm{FePc}$ macrocyclic complexes on OPG, SWCNT and py-SWCNT in $0.1 \mathrm{M} \mathrm{NaOH} \mathrm{N}_{2}$-saturated at $100 \mathrm{mV} \mathrm{s}^{-1}$ ( electrode area: $0.196 \mathrm{ch}^{2}$ ) .

Figure 7 compares polarization curves for the oxygen reduction reaction for a rotating graphite disk electrode modified with: ( a) FePc and (166) Cl) FePc directly adsorbed on SWCNTs and axially coordinated to py-SWCNT. These LSV curves are bell-shaped, which is typical of the response of ORR on many $\mathrm{FeN}_{4}$ complexes. The lack of a well-defined diffusion-limited current density can be attributed to the formation of $\mathrm{Fe}(\mathrm{I})_{4}$ more negative potentials and $\mathrm{Fe}(\mathrm{I})$ seems to be less selective for a 4-electron reduction of $\mathrm{O}_{2}$ than $\mathrm{Fe}(\mathrm{II}[\mathrm{)} 88]$ The difference in the shape of polarization curves are not only attributed to catalytic effects but also to the different surface concentrations of the Fe phthalocyanines per geometric area of the electrode. The surface concentrations as $\log \Gamma$ are shown 
in Table II.

The promotion of oxygen reduction in alkaline media for Fe-phthalocyanine-py-SWCNT composite is attributed to the change of coordination and geometry of the complex ( pentæoordinated) , causing that the active site of $\mathrm{Fe}$ be more positive than four-coordinated Fe-phthalocyanine-SWCNT system.[51] In addition, the presence of electron-withdrawing substituents on the Fe-complex causes an additional contribution to the electrocatalytic effect for ORR. In Figure $7 \mathrm{a}$ and $\mathrm{b}$, the polarization curves indicate that the FeN4-py-SWCNT systems shift the onset potential to $11-12 \mathrm{mV}$ more positive compared to the same complex adsorbed on pristine SWCNTs. Moreover, when comparing both axially coordinated systems, the onset potential shifts ca. $40 \mathrm{mV}$ to more positive for 16( Cl) FeBy-SWCNT compared to FePc-py-SWCNT, tracking somehow the shift of the $\mathrm{Fe}(\mathrm{III}) / \mathrm{Fe}$ ( pditential. The coordination of both axial positions in FePc ( octahedral complex geometry) isenergetically much more favorable than the single axial site coordination ( square pyramidal geometry of the complex) A parameter that reflects the overall ORR mechanistic pathway is the percentage of peroxide formed. For Fe-N 4 catalysts, the ORR typically involves a four-electron transfer pathway to produce $\mathrm{H}_{2} \mathrm{O}$ without any detectable amounts of $\mathrm{H}_{2} \mathrm{O}_{2}$. [89] In addition, the presence of peroxide is not a desirable product since it can decrease the catalyst stability in a fuel cell.[48] The kinetics of the ORR on the catalysts was evaluated quantitatively by polarization curves taken on a rotating ring-disk electrode ( RRDE). The peroxide yield and the number of electron transferred $(n) \quad$ was calculated by the following equation 590$]$

$$
\begin{aligned}
& \% \mathrm{H}_{2} \mathrm{O}_{2}=\frac{100 \times 2 I_{r}}{\left(I_{d}+I_{r}\right) / N} \\
& n=4 \frac{I_{d} \times N}{I_{d} N+I_{r}}
\end{aligned}
$$

where $I_{\mathrm{d}}$ is disk current, $I_{\mathrm{r}}$ is ring current and $N$ is the collection efficiency of the Pt ring. For Fe- 
phthalocyanine-py-SWCNT catalysts, the $\% \mathrm{H}_{2} \mathrm{O}_{2}$ is lower $(0.04 \%)$ than - $p$ bthalocyanineSWCNT. Also, the number of transferred electrons for all systems is close to four, which confirms that essentially the electroreduction of oxygen proceeds via the transfer of 4 electrons. ${ }^{17,24,50,79,80}$

Mass-transport corrected Tafel plots of kinetic current density versus applied potential are shown in Figure 8. For the FeN4-py-SWCNT catalysts, the Tafel slopes are close to -0.031 to $-0.033 \mathrm{~V} \mathrm{dec}^{-1}$ ( Table II) at low overpotentiaFsor our case, the two first elementary steps of ORR on FeN4 macrocycles can be described as Eqs. [3-4], a mechanism generally proposed in the literature. If one assumes Eq 3 to be the rate-determining step, one would expect a Tafel slope of $120 \mathrm{mV} \mathrm{dec}{ }^{-1}$, not in line with experiment. However, if one assumes Eq 4 to be the rate determining step, then a Tafel slope close to $-0.039 \mathrm{~V} \mathrm{dec}^{-1}$ can be expected in the potential region where the surface concentration of $\mathrm{Fe}(\mathrm{II})$ is potentidendent: ${ }^{82}$

$\left[\mathrm{Fe}(\mathrm{III}) \mathrm{QHH}+\mathrm{e}^{-} \rightleftharpoons\left[\mathrm{Fe}\left(\mathrm{II}_{\partial \mathrm{d}}\right]+\mathrm{OH}^{-}\right.\right.$

$\left[\mathrm{Fe}\left(\mathrm{II}_{2 \mathrm{~d}}\right]+\mathrm{O}_{2}+\mathrm{e}-->\left[\mathrm{Fe}(\mathrm{II})_{2}\right] \mathrm{Qd}_{\mathrm{d}} r d s\right.$
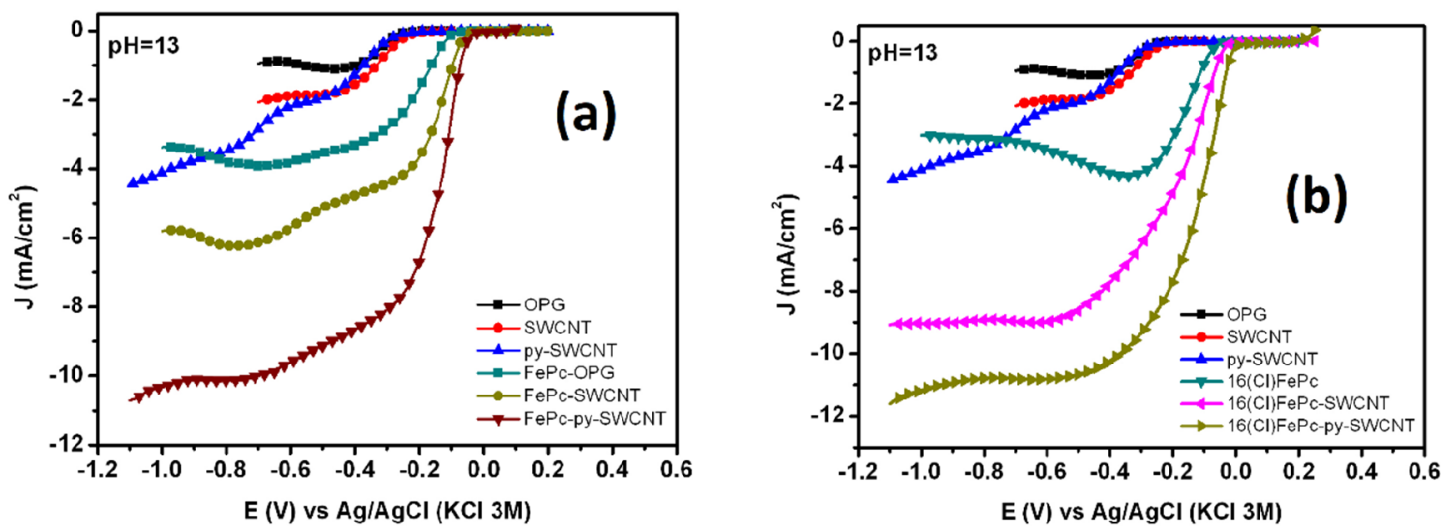


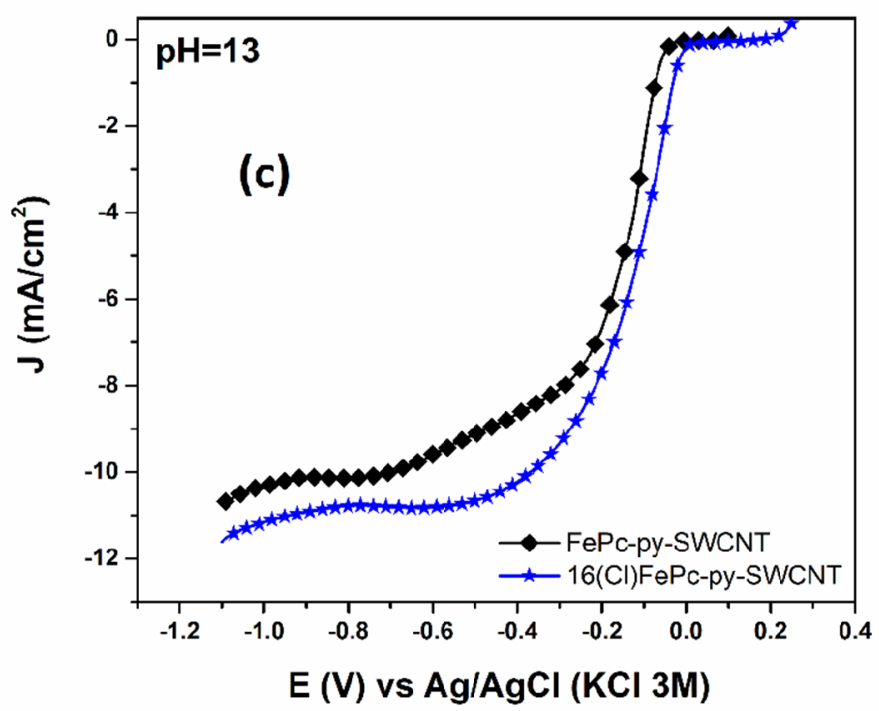

Figure 7. $\mathrm{RDE}$ polarization curves for $\mathrm{O}_{2}$ reduction on: ( a) FePc and ( b) 16( Gityadhelleto OPG, SWCNT/OPG and py-SWCNT/OPG electrodes ( c) comparisons of the best catalysis. 0.1 $\mathrm{M} \mathrm{NaOH}$ solution saturated with $\mathrm{O}_{2}$. Electrode rotation rate: $1600 \mathrm{rpm}$, scan rate: $5 \mathrm{mV} \mathrm{s}^{-1}$ and carbon nanotube loading of $50 \mu \mathrm{g} \mathrm{cm}$.

Table II. Electrochemical parameters: Formal potentials, Tafel slopes and $\log \Gamma$ values for ORR on unmodified and modified OPG electrodes in $0.1 \mathrm{M} \mathrm{NaOH}$ solution.

\begin{tabular}{|c|c|c|c|c|c|}
\hline Catalyst & $\begin{array}{c}E_{(\mathrm{Fe}(\mathrm{III}) / \mathrm{Fe}(\mathrm{II})} \\
(\mathrm{V} \text { vs. } \mathrm{Ag} / \mathrm{AgCl}, \\
\mathrm{KCl} 3 \mathrm{M})\end{array}$ & $\begin{array}{l}E_{(\mathrm{Fe} \text { (II) } / \mathrm{Fe}(}^{\mathrm{o}} \\
\text { ( V vs. } \\
\mathrm{Ag} / \mathrm{AgCl}, \\
\mathrm{KCl} 3 \mathrm{M}) \\
\end{array}$ & $\begin{array}{c}\text { Tafel slope } \\
\left(\mathrm{Vdec}^{-1}\right)\end{array}$ & $n$ & $\begin{array}{c}\log \Gamma(\mathrm{mol} \\
\left.\mathrm{cm}^{-2}\right)\end{array}$ \\
\hline FePc-OPG & -0.131 & -0.646 & -0.046 & & -10.438 \\
\hline FePc-SWCNT & -0.157 & -0.643 & -0.036 & 3.99 & -9.517 \\
\hline FePc-py-SWCNT & -0.129 & -0.589 & -0.031 & 3.99 & -8.242 \\
\hline 16( Cl) FePPG & -0.017 & -0.359 & -0.044 & 3.99 & -10.078 \\
\hline $16(\mathrm{Cl}) \mathrm{FeBWCNT}$ & -0.005 & -0.225 & -0.036 & 3.99 & -8.672 \\
\hline 16( Cl) FeBy-SWCNT & 0.065 & -0.231 & -0.033 & 3.99 & -8.244 \\
\hline
\end{tabular}




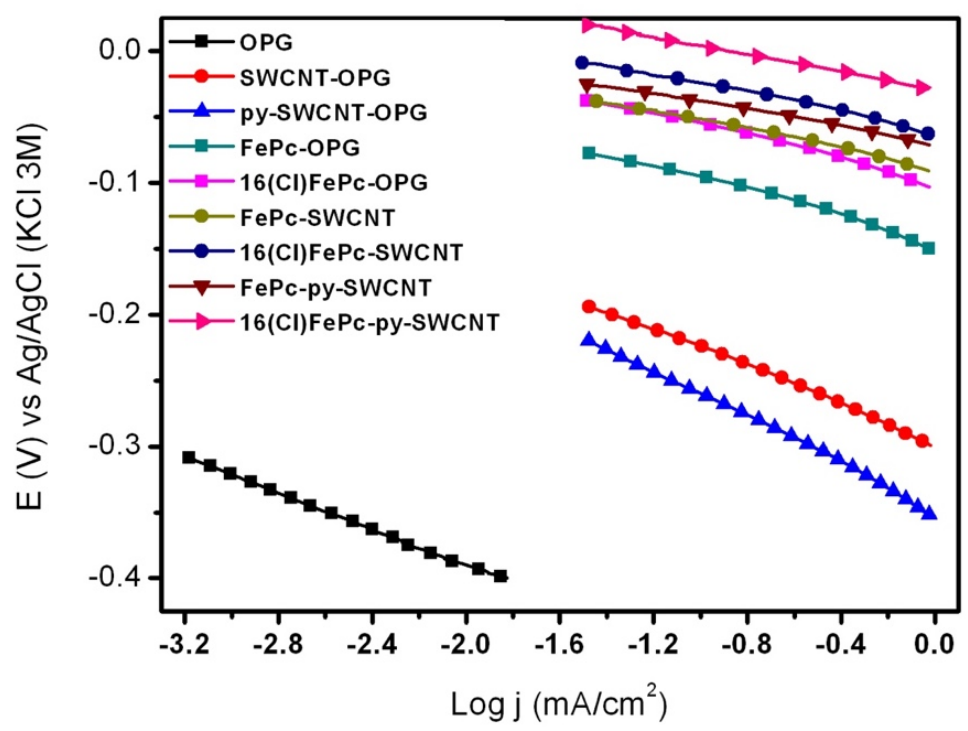

Figure 8. Tafel plots for oxygen reduction reaction in $0.1 \mathrm{M} \mathrm{NaOH}$ on OPG electrodes modified with $\mathrm{FeN}_{4}-\mathrm{SWCNT}$ and $\mathrm{FeN}_{4}$-py-SWCNT. Data derived from Figure 7.

Since the electrodes exhibit different densities of active sites it is important to compare the activities by normalizing to $\Gamma$, the surface coverage observed with smooth OPG electrodes. $\Gamma$ can be estimated from the electrical charge under the redox observed in Figure 6 after substracting the capacitive background currents so $\Gamma=Q / n F A$ where $\mathrm{Q}$ is the electrical charge in $\mathrm{Cb}, \mathrm{n}=1$ for redox process involving the $\mathrm{Fe}$ center, $F$ is the Faraday constant and $A$ is the area of the electrode in $\mathrm{cm}^{2}$. Figure 9 show the plots of electrocatalytic activity expressed as $\log (j / x)$ measured constant overpotential vs the ORR where $\mathrm{x}=\Gamma_{\mathrm{FePc}-\mathrm{SWCNT} /} \Gamma_{\mathrm{FePc}-\mathrm{OPG}}$ or $\Gamma_{\mathrm{FePc}-\mathrm{py}-\mathrm{SWCNT} /} \Gamma_{\mathrm{FePc}-\mathrm{OPG}} . \Gamma_{\mathrm{FePc}-\mathrm{OPG}}$ is the surface concentration of FePc on OPG and $\Gamma_{\text {FePc-SwCNT }}$ or $\Gamma_{\text {FePc-py-SwCNT }}$ are the surface concentrations of FePc on SWCNT or py-SWCNT, so $\mathrm{x}$ is greater than unity for SWCNT-coated electrodes, which are rougher than smooth OPG electrodes. The same applies in the case of systems with $16(\mathrm{Cl}) \mathrm{FePc}$. The correction for the factor $\mathrm{x}$ was done as the surface concentration of FePc change for each SWCNT used and are much higher than those on OPG. This correction carries the assumption that the reaction is first order in $[\mathrm{FePc}]_{\mathrm{ad}}$. 


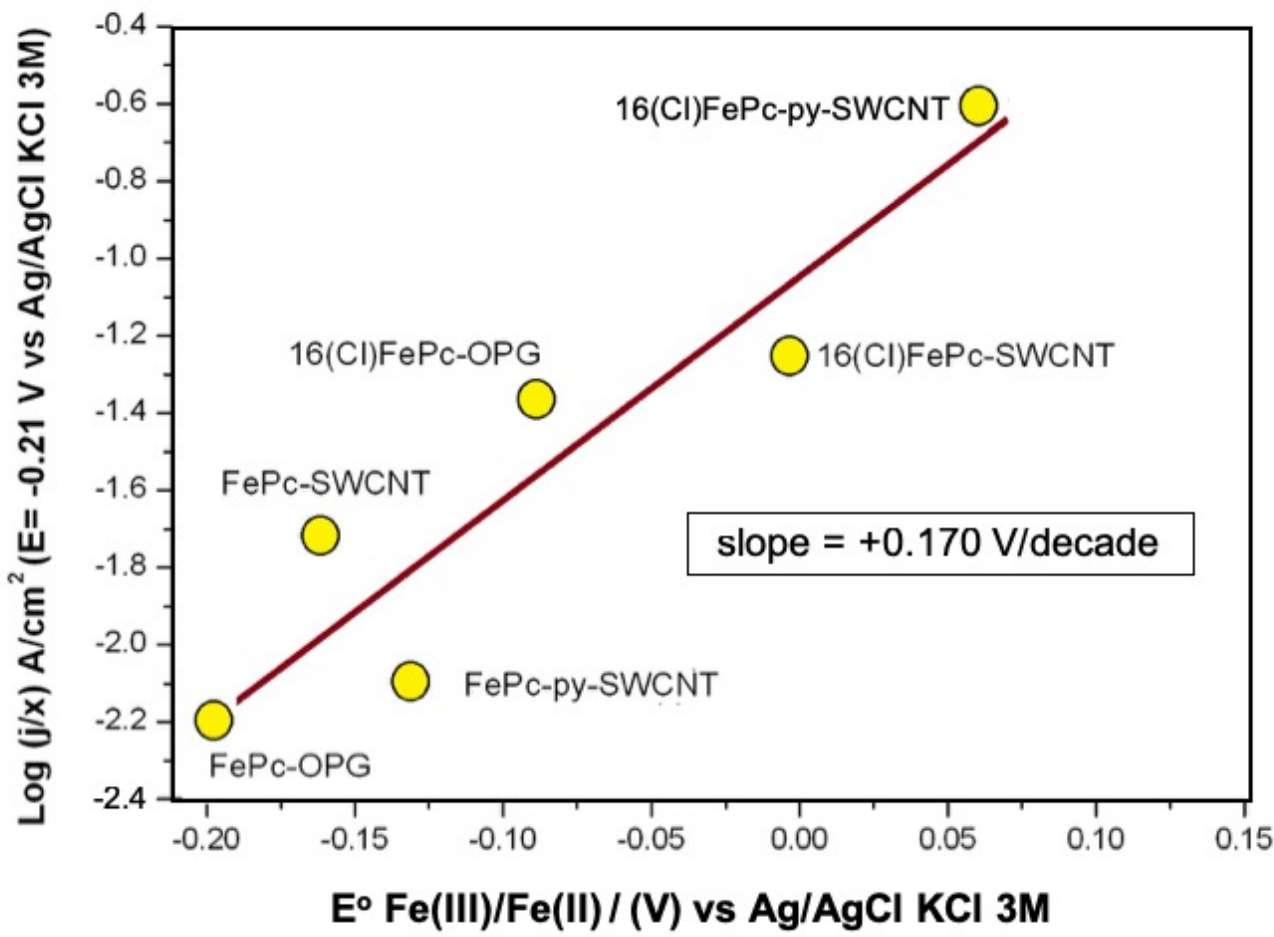

Figure 9. Plot of electrocatalytic activity as $\log (j / \mathrm{x})$ measured at $-0.21 \mathrm{~V}$ for ORR vs. the formal potential of $\mathrm{Fe}(\mathrm{III}) /($ II) .

Figure 9 compares the catalytic activity of the different electrodes, at a constant potential. The $\mathrm{O}_{2}$ reduction currents have been normalized to the real number of active sites ( assuming all active sites give a signal in a cyclic voltammogram in the absence of $\mathrm{O}_{2}$ ).. $\mathrm{X}$ was estimated from the electrical charges under the $\mathrm{CV}$ peaks of FePc as: $\mathrm{x}=\mathrm{Q}_{\mathrm{OPG}} / \mathrm{Q}_{\text {SwCNT }}$ where $\mathrm{QOPG}$ is the average electrical charge under the redox peaks of FePc adsorbed on OPG and Q swCNT is the average electrical charge under the redox peaks of FePc adsorbed or anchored on the external walls of SWCNTs. It is remarkable that the reactivity trend is exactly that observed previously for several metal phthalocyanines of $\mathrm{Cr}$, Mn and Fe adsorbed on OPG ( see Figure 10 that includes the data obtained in the present work) . 

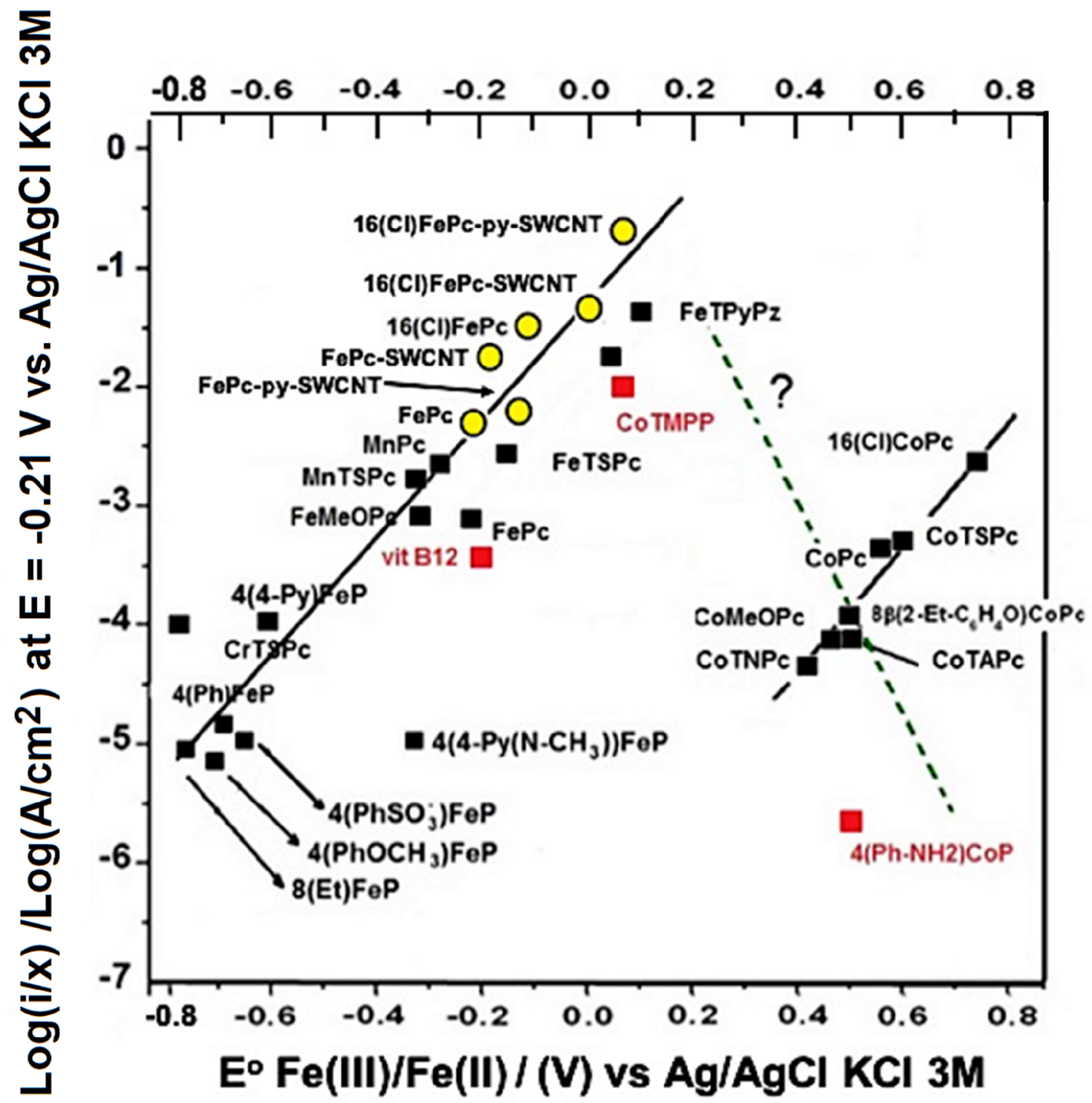

\section{$\mathrm{E}^{\circ} \mathrm{Fe}(\mathrm{III}) / \mathrm{Fe}(\mathrm{II}) /(\mathrm{V})$ vs $\mathrm{Ag} / \mathrm{AgCl} \mathrm{KCl} 3 \mathrm{M}$}

Figure 10. Volcano plots of electrocatalytic activity as $\log (j / x)$ measured at $-0.21 \mathrm{~V}$ for ORR vs. the $\mathrm{Fe}(\mathrm{III}) /\left(\right.$ II) formal potential caftahest. All data measured in $\mathrm{O}_{2}$ saturated $0.1 \mathrm{M} \mathrm{NaOH}$ solution. The currents for SWCNT and py-SWCNT have been normalized to the surface coverage $(I)$ of FePc or $16(\mathrm{Cl}) \mathrm{FePc} / \mathrm{SWCNT}$ compared to that for $\mathrm{FeBc} 16(\mathrm{Cl}) \mathrm{FePc} / \mathrm{OPG}$. The data in circlesas obtained in this work. Adapted from Figure 6 in reference.[33]

It is interesting to note that the new data reported in this work fall on one side of a volcano correlation reported before [33]. This side of the volcano corresponds to the strong binding region so essentially electron withdrawing groups on the ligand decrease the $\mathrm{Fe}-\mathrm{O}_{2}$ binding energy and move the catalyst to the top of the volcano correlation. In our recently published paper we consider that the two linear 
correlations seem to be part of an incomplete volcano correlation as illustrated in the right side of Figure 10. However, when plotting activities as ( loige versus the $\mathrm{M}-\mathrm{O}_{2}$ binding energies to the $\mathrm{MN} 4$ catalysts, a volcano correlation is indeed obtained [33], which is essentially similar to what is observed for metal electrodes. These two volcano correlations have something in common, in both correlations ( metal catalysts versus MN4 molecular catalysts)-ełectron reduction catalysts appear on the same side of the volcano, i.e. the strong $\mathrm{M}-\mathrm{O}_{2}$ binding side. On the weak binding side appear the two-electron reduction catalysts.

Another interesting reactivity descriptor for ORR that is becoming very common is the turnover frequency that is defined as

$$
\operatorname{TOF}\left[\mathrm{s}^{-1}\right]=\frac{i\left[\mathrm{Acm}^{-2}\right]}{n \cdot Q_{M, e f f e c t i v e}\left[\mathrm{C} \mathrm{cm}^{-2}\right]}
$$

Where $I$ is the experimental current density, $n$ is the total amount of electrons transferered per $\mathrm{O}_{2}$ molecule, which in our case is equal to 4 , and electrical charge of $\mathrm{M}(\mathrm{II})$ active species 1 , active . It is well accepted that M( II) species are active for ORR, especially in alkaline media where M( species bind $\mathrm{OH}$ very strongly and are then inactive. The fraction of catalyst in the M( II) stateany potential can be estimated using the Nernst equation for adsorbed species, assuming ideal behavior as:

$$
\theta M(I I)=\frac{\exp \left(F\left(E-E_{I I / I}^{0}\right) / R T\right)}{\left[1+\exp \left(F\left(E-E_{I I / I}^{0}\right) / R T\right)\right]} \frac{1}{\left[1+\exp \left(F\left(E-E_{I I I / I I}^{0}\right) / R T\right)\right]}
$$

All catalysts studied present $E_{I I / I}^{\circ}$ values that are well below the experimental potentials studied for ORR, the first term in the above equation is equal to unity so $\theta \mathrm{M}($ II) is given by:

$$
\theta \mathrm{M}(\mathrm{II})=\frac{1}{\left[1+\exp \left(F\left(E-E_{I I I / I I}^{0}\right) / R T\right)\right]}
$$


The effective charge that accounts for the real number of active sites is $\mathrm{Q}_{\mathrm{M} \text { effective }}=\theta \mathrm{M}($ II) Qtotal since $\mathrm{Fe}($ IIll)s not active for ORR.

For catalysts that have $E^{\circ} \mathrm{M}($ III) ( II) pedtentials much more positive than the working potentials at which catalytic currents are observed $\theta \mathrm{M}($ II $)$ is equal to unity. But this not true for some catalysts. The electrical charges of metal-centered redox processes estimated form the voltammetries do not represent the total number of active sites, because the surface concentration of $\mathrm{Fe}($ II) is potential dependent. It is possible that some $T O F$ values reported in the literature are not accurate if the currents used for its estimation where measured at potentials too close to $E^{\mathrm{o}} \mathrm{M}$ ( III) /( II) .
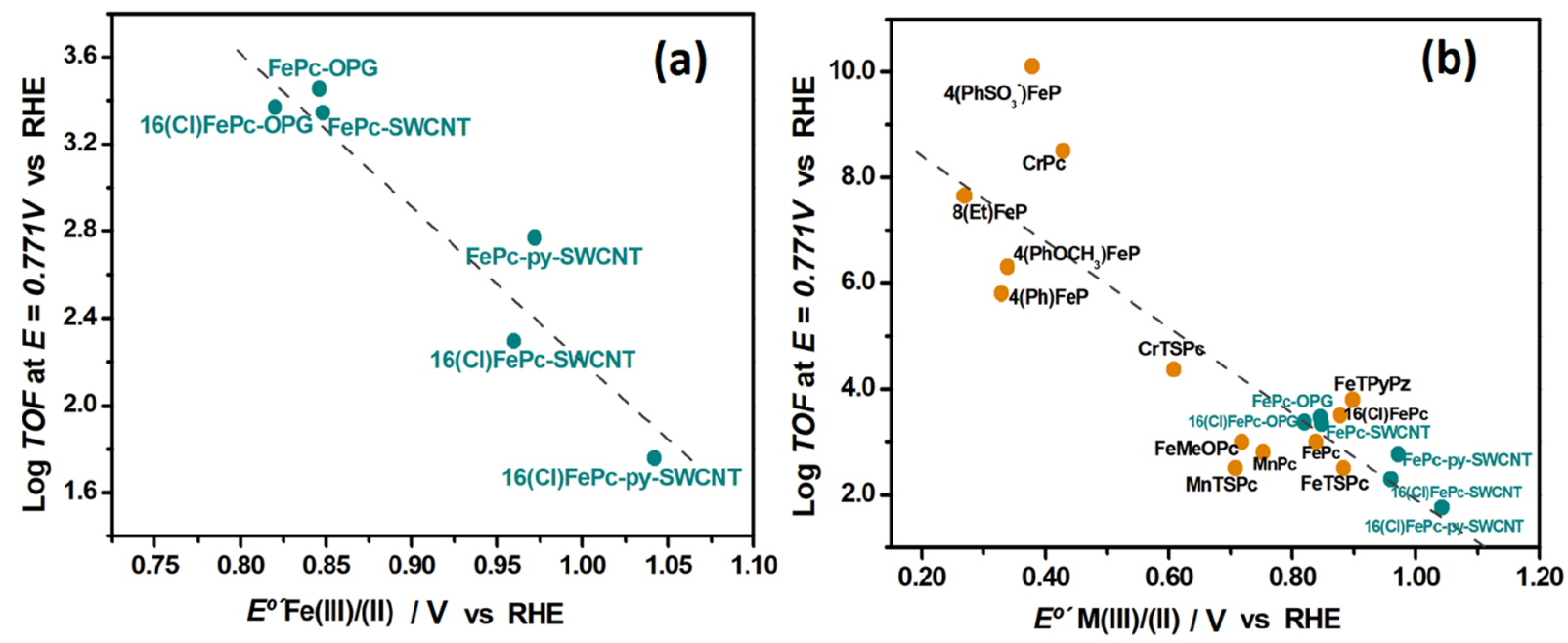

Figure 11 (a) Log TOF plot versus the Fe( III) /( II) formal potential of the FeN4 catalysts under different configuration. ORR in $0.1 \mathrm{M} \mathrm{NaOH}$. ( b\$similar plot to Figure 11( a) but including additional data from the literature[34].

The slope of the line in Figure $11-\mathrm{a}$ as $\delta E^{\circ} /(\delta \log T O F)_{E}$ is $-0.128 \mathrm{~V} \mathrm{dec}^{-1}$ whereas the slope of Figure $11-\mathrm{b}$ is $-0.125 \mathrm{dec}^{-1}$. These slopes are close to $R T / \beta F$ and can be considered Brönsted slopes as in previous work it has been shown that the $\mathrm{M}-\mathrm{O}_{2}$ binding energy, a reactivity descriptor, is directly correlated to the $\mathrm{E}^{\circ}$ ' $\mathrm{M}$ ( III) /( II) formal potSittimle catalysts studied in this work follow a similar trend in reactivity of a large number of catalysts studied before and simply adsorbed on OPG. The 
reactivity per active site increases as the driving force of the catalyst increases ( moregradually negative $E^{\circ}$ values) so the correlations in Figure 11 can be considered linear free energy relationships. The $E^{\circ}, \mathrm{M}(\mathrm{III}) /(\mathrm{II})$ redox potential therasaats additional driving force to the applied potential and contributes then to lower the activation energy of the process in a similar way to the $\mathrm{M}-\mathrm{O}_{2}$ binding energy. The non-linear volcano correlation disappears when TOF values are used instead of currents because the decrease in activity for catalysts that have very negative M( III) /( II) redox potentials is attributed to thferdotion of atomically dispersed M( II) species at the potentials where ORR currents are observed. So high TOF values in this case do not mean high catalytic activities. In this case the low surface concentration of active sites on one side of the volcano correlation in Figure 10 dramatically decreases the currents as the reaction is presumably first order in surface concentration of $\mathrm{Fe}$ ( II) sitest the activity per active sites increases in that region of the volcano, similarly to homogeneous catalytic redox processes[49]

According to the Sabatier Principle,[33] for maximum catalytic activity the energy of the binding of the reacting molecule needs to be moderate, i.e. not too strong, not too weak and essentially explains the shape of the correlation where low activity is observed for both low $\mathrm{M}-\mathrm{O}_{2}$ binding and high $\mathrm{M}$ $\mathrm{O}_{2}$ binding energy regions of the complete volcano correlation. The shape of the volcano can also be explained using a Langmuir isotherm that essentially defines the fraction of atomically dispersed of Fe centers occupied with $\mathrm{O}_{2}(\theta)$, i.e. fraction of $\mathrm{M}-\mathrm{O}_{2}$ species present on the catalytic surface in relation to the total of Fe sites. Catalysts binding $\mathrm{O}_{2}$ very weakly give very low values of $\theta$ and low activities and the opposite is true for catalysts binding $\mathrm{O}_{2}$ very strongly which give values of $\theta$ close to unity, and in that case practically all the surface sites are occupied with $\mathrm{O}_{2}$ bound intermediates, blocking the active sites and again give very low activities. These two extreme cases represent the foothills of both sides of the volcano correlation. For the particular case of the reduction of $\mathrm{O}_{2}$, but similar derivations can be shown for other electrochemical reactions: 
$\left.\Delta \mathrm{G}^{\circ} 2 \quad\left[\mathrm{MN}_{4}\right]_{\mathrm{ad}}+\mathrm{O}_{2(\text { aq }}\right)^{-} \mathrm{e}^{-} \rightarrow\left[\mathrm{O}_{2}-\mathrm{MN}_{4}^{-}\right]_{\mathrm{ad}}$

Depending on the catalyst this equation will be shifted to the product ( strong adsorption) or to the reactants ( weak adsorptionbut it is also a potential-dependent process. It is important to emphasize that reaction ( 4 ) is not at equilibriumhe kinetic current density for a given potential and $\Delta G^{\circ}$ ad consistent with the Butler-Volmer formalism is given by the following equation:

$$
i=\mathrm{n} F k \Gamma_{\mathrm{M}(\mathrm{I} / \mathrm{O} 2}\left(\begin{array}{lll}
1 \theta) & \exp \beta F E / \mathrm{RT}) & \left.\exp \beta^{\prime} \Delta G^{\circ}{ }_{\mathrm{ad}} / \mathrm{RT}\right)
\end{array}\right.
$$

Since ORR is an irreversible reaction we can ignore the anodic contribution to the process. Parameters: $\mathrm{n} F, k$ adjustable and $n=4$ in our case, $E$ adjustable (vs SCE) $\beta$ and $\beta^{\prime}$ approximately 0.5 , $\Delta G^{\circ}$ ad $=n F E^{\circ}+\mathrm{C}$, where $E^{\circ}=$ formal potential of each catalyst $0<\theta_{\mathrm{M}(\text { IIF }} 1$ depending on $E$, $\mathrm{C}$ is a constant.[33] Very negative values of $E^{\circ}$ correspond to strong $\mathrm{O}_{2}$ binding to $\mathrm{Fe}$ and the opposite is true for more positive $E^{\circ}$, values.

The first exponential factor in equation ( i) comes from the Butleolmer equation and the second from the fact that the reactant adsorbs in a concerted fashion with the one-electron-transfer step. $\mathrm{c}_{\mathrm{O} 2}$ is the surface concentration of $\mathrm{O}_{2}$ at the interface, equal to the bulk concentration in the absence of mass-transport limitations, $\Gamma_{\mathrm{M}}$ IIjs the surface concentration of the complex in the $\mathrm{M}($ II) active state, $(-\theta)$ is the fraction ofatomically dispersed $\mathrm{Fe}$ active sites that are not occupied by ORR intermediates and $\Delta G^{\circ}$ ad is the free energy of adsorption of $\mathrm{O}_{2}$ on the $\mathrm{M}$ active sites. The rest of the terms have their usual meaning. The coverage of adsorbed $\mathrm{O}_{2}$ can be assumed to follow a Langmuir isotherm as in:

$$
\theta=\frac{\mathrm{p02} \exp \left(\frac{-\Delta G_{{ }^{\circ} \mathrm{CO2}}}{R T}\right)}{\left[1+\mathrm{pO2} \exp \left(\frac{-\Delta G^{\circ}{ }^{\circ O 2}}{R T}\right)\right]}
$$

In volcano plots, the activities for different catalysts are compared at constant $E$, so the ButlerVolmer exponential term, for simplicity can be included into a constant $k^{\prime}$ as $k^{\prime}=k \exp (-\beta F E / R T)$ . For small coverages $\Delta G^{\circ} \mathrm{O} 2$ is positive so equation ( i) can be written as: 


$$
\begin{aligned}
& i=\mathrm{nF} k^{\prime} \Gamma_{\mathrm{M}}\left(\operatorname{IpO}_{2}\left(-\theta_{\mathrm{ad}}\right) \quad \exp \beta^{\prime} \Delta G^{\circ}{ }_{\mathrm{ad}} / \mathrm{RT}\right) \\
& (-\theta)=\frac{1+\mathrm{pO} 2 \Gamma \mathrm{M}(\mathrm{II}) \exp \left(\frac{-\Delta G^{\circ}{ }_{O 2}}{R T}\right)}{\left[1+\mathrm{pO} 2 \exp \left(\frac{-\Delta G^{\circ} O 2}{R T}\right)\right]}-\frac{\operatorname{pO} 2 \Gamma \mathrm{M}(\mathrm{II}) \exp \left(\frac{-\Delta G_{O 2}^{\circ}}{R T}\right)}{\left[1+902 \exp \left(\frac{-\Delta G^{\circ}{ }^{\circ}}{R T}\right)\right]} \\
& (-\theta)=\frac{1}{\left[1+\mathrm{pO} 2 \exp \left(\frac{-\Delta G_{O 2}}{R T}\right)\right]} \\
& i=\frac{\mathrm{nFk}^{\prime} \Gamma \mathrm{M}(\mathrm{II}) \mathrm{pO} 2 \exp \left(-\beta^{\prime} \Delta G^{\circ} \mathrm{O} 2 / \mathrm{RT}\right)}{\left[1+\mathrm{pO} 2 \exp \left(\frac{-\Delta G_{O 2}}{R T}\right)\right]}
\end{aligned}
$$

Equation ( v) essentially describes the shape of the volcano plot and that the maximum current density will be observed for $\Delta G^{\circ} \mathrm{O} 2=0$ and the maximum current at the apex of the volcano is:

$$
i=\mathrm{nFk}^{\prime} \Gamma_{\mathrm{M}}\left(\mathrm{m} \mathrm{p}_{2} /\left[1+\mathrm{C}_{\mathrm{O} 2}\right]\right.
$$

For strong adsorption $\Delta G^{\circ} \mathrm{O} 2$ is large and has a negative sign so $1<<\operatorname{po}_{\mathrm{O} 2} \exp \left(-\Delta G_{\mathrm{O} 2} / \mathrm{RT}\right)$ so the general equation ( v) becomes:

$$
i=\mathrm{nF} k^{\prime} \Gamma_{\mathrm{M}}\left(\operatorname{Igxp}\left(+\not{ }^{\circ} G^{\circ} \mathrm{O} 2 / \mathrm{RT}\right) \quad\right. \text { ( vii) strong adsorption }
$$

Equation ( vii) explains the linear correlation in the region of strong adsorption and is essentially independent of the concentration of the reactant, in this case, $\mathrm{O}_{2}$. It is important to point out that all catalysts examined in this work are located on the strong $\mathrm{Fe}-\mathrm{O}_{2}$ binding region of the volcano correlation [33] so they follow equation ( viiand the ORR process is occurring on a partially covered surface. The beneficial role of the axial biding ligand is to decrease the $\mathrm{O}_{2}$ binding energy and to move the catalysts towards the apex of the volcano, as illustrated in Figure 10. This is also evidenced by the shift of the $\mathrm{Fe}(\mathrm{III}) /(\mathrm{II})$ redox potential to more positive values as a result of the electron withdrawing effect of the axial ligand.

For weak adsorption $\Delta \mathrm{G}^{\circ} \mathrm{O} 2$ is very positive, the term $\mathrm{p}_{\mathrm{O} 2} \exp \left(-\Delta G^{\circ} \mathrm{O} / \mathrm{RT}\right) \quad<1$ in equation ( v) vanishes and the general equation ( v) simfipds to:

$$
i=\mathrm{nFk}^{\prime} \Gamma_{\mathrm{M}}\left(\mathrm{IpO}_{2} \exp \left(-\beta^{\prime} \Delta G^{\circ} \mathrm{O} / \mathrm{RT}\right) \quad\right. \text { ( viii) weak adsorption }
$$


This equation can also be obtained from equation ( iii) by simply ignorißghat tends to zero. So, equations ( vii) and ( viii) describe both linear correlations in the volcano plots with slopes of different signs, i.e. $+\mathrm{RT} / \beta^{\prime} \mathrm{F}$. for the strong adsorption region and $-\mathrm{RT} / \beta^{\prime} \mathrm{F}$ for the weak adsorption region. According to this, the volcano plot should be symmetrical since both legs of the volcano have the same absolute slope value. It is necessary to clarify that in theoretical calculations the binding energy $\Delta E_{\mathrm{bO} 2}$ is used because it does not contain entropy terms as $\Delta G^{\circ} \mathrm{O} 2$ and the entropic terms are difficult to estimate. The binding energy is essentially the energy to break the $\mathrm{M}-\mathrm{O}_{2}$ bond. Since $\Delta G^{\circ} \mathrm{O} 2={ }_{\mathrm{E}^{\circ}}$, It is important to point out that $\beta$ is the symmetry factor of the one-electron-transfer energy barrier and $\beta^{\prime}$ is a Brpnsted factor, essentially similar to $\beta$ but related to the effect of $\mathrm{O}_{2}$ adsorption on the energy barrier. Both equations ( vii) and ( viëdictpthat the currents increase from positive $\Delta G^{\circ}$ ad ( weak adsorption) to negative ( strong adsorption) valdes ${ }^{\circ}$ f but up to one point. As the fraction of adsorbed intermediates $\theta$ increases the currents start to decrease. This originates the "falling" side of the volcano for electrode materials the term $(-\theta)$ tends to zero a $\theta \rightarrow 1$. This corresponds to the left side of the volcano correlation in Figure 10.

As $\Delta G^{\circ}{ }_{\text {ad }}=F E^{o}+$ C. we can rewrite equations ( vii) and ( viii) as a functFon:of

$$
\begin{aligned}
& i=\mathrm{nFk}{ }^{\prime} \Gamma_{\mathrm{M}(\operatorname{Igxp}}\left(+\mid F E^{\circ} / \mathrm{RT}\right) \quad(\text { ix }) \text { strong adsorption } \\
& i=\mathrm{nF}^{\prime} \Gamma_{\mathrm{M}(\mathrm{IpO}} \exp \left(-\beta^{\prime} F E^{\circ} / \mathrm{RT}\right) \quad(\mathrm{x}) \text { weak adsorption }
\end{aligned}
$$

The slope of the volcano correlation of the strong binding region in Figure 10 which groups the catalysts studied in this work is ca. +0.2 Vdecade $^{-1}$. This is above a value of +0.12 Vdecade $^{-1}$

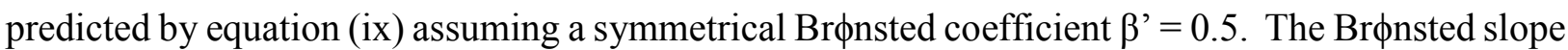
in Figure 10 suggests a value of $\beta^{\prime}=0.3$ and if this value is reflecting an unsymmetrical energy barriers for the adsorption step of $\mathrm{O}_{2}$ to the $\mathrm{Fe}$ centers the reason for this asymmetry need to be investigated in more detail or to study more catalysts bearing a FeN4 active site. 


\section{CONCLUSIONS}

In summary, FePc-py-SWCNT and 16( $\mathrm{Cl})$ Fepy-SWCNT assemblies were successfully obtained. The characterization of these systems using Raman spectroscopy shows changes in the intensity ratio of the $\mathrm{D} / \mathrm{G}$ signals attributed to the presence of pyridine molecules covalently linked to the walls of carbon nanotubes and that this changes the hybridization of the carbon atoms from $\mathrm{sp}^{2}$ to $\mathrm{sp}^{3}$. In addition, the XPS analysis indicated that the presence Fe atoms mostly in the Fe( III) state the absence of an applied potential and pyridine-type nitrogen play key roles in enhancing the ORR activity. XANES analyses suggests a five-coordinated structure for FePc-py-SWCNT and 16( Cl) FeBy-SWCNT.

Cyclic voltammetry shows that the electron-withdrawing effect of the $-\mathrm{Cl}$ groups on the ligand in 16( Cl) FePc immobilized on SWCNTs and-pyWCNT causes a shift of both $\mathrm{Fe}(\mathrm{II}) / \mathrm{Fe}(\mathrm{I})$ and $\mathrm{Fe}(\mathrm{III}) / \mathrm{Fe}(\mathrm{II})$ redlos to more positive potentials compared to H-substituted FePc. Linear sweep voltammetry results demonstrated that the introduction of -py groups to SWCNT and coordinated to iron phthalocyanine was beneficial in improving the electrocatalytic ORR activity, causing a displacement of the onset potential to more positive values. The activity as ( loig) $E$ follows a linear correlation with $E^{\mathrm{o}}$, ${ }_{\text {III/II }}$ showing once more, as observed in previous work, that more positive $\mathrm{Fe}(\mathrm{III}) /(\mathrm{II})$ redox potentials favor the readthiwever, $\log (T O F)_{E}$ versus $E_{\text {III/II }}^{\mathrm{o}}$ also a follows a linear correlation but the $T O F$ decreases with $E^{o}$, ${ }_{\text {III/II }}$ indicating that the activity per active site increases as the driving force of the catalysts increases ( i.e. more negativ $\mathbb{E}^{\mathrm{o}}{ }_{\mathrm{III} / \mathrm{II}} \mathrm{values}$ ). In general, it can be concluded that a decrease in the electron density on the Fe center caused by axial ligands or by electron-withdrawing groups of the phthalocyanine both increase the catalytic activity of the composite catalysts but decrease the TOF. The data fits rather well one side of a volcano correlation where the activity of a great variety of $\mathrm{Cr}, \mathrm{Mn}$ and FeN4 catalysts ( from previous wor) 333 ] is 
compared versus the M( III) /( II) redox potfritially, it can be concluded that any shift in the $\mathrm{Fe}(\mathrm{III}) /($ II) causedplarar ligand or axial ligands are beneficial to the catalytic activity and this seems to be also true for pyrolyzed MN4 catalysts $[33,50,77]$

\section{ACKNOWLEDGMENTS}

This study was financially supported by National Doctoral Fellowship Conicyt No. 21130168, Fondecyt Project No. 1140199 and 1140192, Millennium Nucleus of Molecular Engineering for Catalysis and Biosensors RC120001, Anillo Project ACT 192175 and Dicyt-USACH. Nataly Silva is grateful for a Postdoctoral Grant No. 3150271. D.C-A acknowledges the financial support of CONICYT/FONDECYT 11170289. Powered@NLHPC: This research was partially supported by the supercomputing infrastructure of NLHPC ( ECM2) .Synchrotron SOLEIL, L'orme des Merisiers, BP 48 Saint Aubin, 91192 Gif-sur-Yvette, France for XANES measurements and analysis is greatly appreciated. The present work was also financially supported by the Estonian Research Council (grant PRG723) and by the EU through the European Regional Development Fund ( TK141, “Advanced materials and high-technology devices for energy recuperation systems") .

\section{REFERENCES}

[1] K. Sasaki, H. Naohara, Y. Choi, Y. Cai, W.F. Chen, P. Liu, R.R. Adzic, Highly stable Pt monolayer on $\mathrm{PdAu}$ nanoparticle electrocatalysts for the oxygen reduction reaction, Nat. Commun. 3 ( 2012) 1111519. https://doi.org/10.1038/ncomms2124.

[2] J. Greeley, I.E.L. Stephens, A.S. Bondarenko, T.P. Johansson, H.A. Hansen, T.F. Jaramillo, J. Rossmeisl, I. Chorkendorff, J.K. Nørskov, Alloys of platinum and early transition metals as oxygen reduction electrocatalysts, Nat. Chem. 1 ( 2009) 5556. https://doi.org/10.1038/nchem.367.

[3] V.R. Stamenkovic, B. Fowler, B.S. Mun, G. Wang, P.N. Ross, C.A. Lucas, N.M. Markovic, Improved oxygen reduction activity on $\mathrm{Pt} 3 \mathrm{Ni}(111)$ via increased surface site availability, Science ( 80$) .315$ ( 2007) -493. https://doi.org/10.1126/science.1135941. 
[4] G. Merle, M. Wessling, K. Nijmeijer, Anion exchange membranes for alkaline fuel cells: A review, J. Memb. Sci. 377 ( 2011)-315.

https://doi.org/https://doi.org/10.1016/j.memsci.2011.04.043.

[5] Y. Wang, K.S. Chen, J. Mishler, S.C. Cho, X.C. Adroher, A review of polymer electrolyte membrane fuel cells: Technology, applications, and needs on fundamental research, Appl. Energy. 88 ( 2011) 98D07. https://doi.org/https://doi.org/10.1016/j.apenergy.2010.09.030.

[6] A. Sarapuu, E. Kibena-Põldsepp, M. Borghei, K. Tammeveski, Electrocatalysis of oxygen reduction on heteroatom-doped nanocarbons and transition metal-nitrogen-carbon catalysts for alkaline membrane fuel cells, J. Mater. Chem. A. 6 ( 2018) 7864. https://doi.org/10.1039/c7ta08690c.

[7] S. Gottesfeld, D.R. Dekel, M. Page, C. Bae, Y. Yan, P. Zelenay, Y.S. Kim, Anion exchange membrane fuel cells: Current status and remaining challenges, J. Power Sources. 375 ( 2018 ) $170-184$.

[8] N. Ramaswamy, S. Mukerjee, Alkaline Anion-Exchange Membrane Fuel Cells: Challenges in Electrocatalysis and Interfacial Charge Transfer., Chem. Rev. 119 ( 2019) 11941979. https://doi.org/10.1021/acs.chemrev.9b00157.

[9] H.A. Firouzjaie, W.E. Mustain, Catalytic Advantages, Challenges, and Priorities in Alkaline Membrane Fuel Cells, ACS Catal. 10 ( 2020) 2234.

https://doi.org/10.1021/acscatal.9b03892.

[10] Y. Liang, Co3O4 nanocrystals on graphene as a synergistic catalyst for oxygen reduction reaction, Nat. Mater. 10 ( 2011) 78186.

[11] K. Gong, Nitrogen-Doped Carbon Nanotube Arrays with High Electrocatalytic Activity for Oxygen Reduction, Science. 323 ( 2009) 76664.

[12] G. Wu, K.L. More, C.M. Johnston, P. Zelenay, High-performance electrocatalysts for oxygen reduction derived from polyaniline, iron, and cobalt, Science ( 80$)$.332 ( 2011) 443-447. https://doi.org/10.1126/science.1200832.

[13] Z.S. Wu, S. Yang, Y. Sun, K. Parvez, X. Feng, K. Müllen, 3D nitrogen-doped graphene aerogel-supported $\mathrm{Fe} 3 \mathrm{O} 4$ nanoparticles as efficient electrocatalysts for the oxygen reduction reaction, J. Am. Chem. Soc. 134 ( 2012) 908D85. https://doi.org/10.1021/ja3030565.

[14] X. Li, B.N. Popov, T. Kawahara, H. Yanagi, Non-precious metal catalysts synthesized from precursors of carbon, nitrogen, and transition metal for oxygen reduction in alkaline fuel cells, J. Power Sources. 196 ( 2011) 1711722.

[15] J. Suntivich, H.A. Gasteiger, N. Yabuuchi, H. Nakanishi, J.B. Goodenough, Y. Shao-Horn, Design principles for oxygen-reduction activity on perovskite oxide catalysts for fuel cells and metal-air batteries, Nat. Chem. 3 ( 2011) 5450. https://doi.org/10.1038/nchem.1069.

[16] S.N.S. Goubert-Renaudin, X. Zhu, A. Wieckowski, Synthesis and characterization of carbon-supported transition metal oxide nanoparticles - Cobalt porphyrin as catalysts for electroreduction of oxygen in acids, Electrochem. Commun. 12 ( 2010) 1457461. 
https://doi.org/10.1016/j.elecom.2010.06.004.

[17] Jasinski R., A New Fuel Cell Cathode Catalyst, Nature. 201 ( 1964$) 1211213$.

[18] M.F. H., Thomas Arthur L., The Phthalocyanines volume 1: Properties and volume 2: Manufacture amd Applications, First Edit, CRC, Boca Raton, Florida, U.S.A., 1983.

[19] K. Heinz, F. Steinbach, Katalyse an Phthalocyaninen, Georg Thieme Verlag, Stuttgart, 1973.

[20] J. Manassen, Metal complexes of porhyrin like compounds as heterogeneous, Catal. Rev. Sci. Eng. 9 ( 1974) -37h.

[21] Gordon A. Melson, Coordination Chemistry of Macrocyclic Compounds, 1 st, Plenum Press, New York, 1979.

[22] C.C. Leznoff, A.B.P. Lever, Phthalocyanines: Properties and Applications Volumen 3, VCH Weihnheim, New York, 1993.

[23] J.H. Zagal, Metallophthalocyanines as catalysts in electrochemical reactions, Coord. Chem. Rev. 119 ( 1992) -886. https://doi.org/10.1016/0010-8545( 92) 800B1

[24] J. Zagal, S. Griveau, J.F. Silva, T. Nyokong, F. Bedioui, Metallophthalocyanine-based molecular materials as catalysts for electrochemical reactions, Coord. Chem. Rev. 254 ( 2010) 2725791.

[25] J. H. Zagal, I. Ponce, R. Oñate, Redox Potentials as Reactivity Descriptors in Electrochemistry, in: I. Ponce ( Ed.) ,dRex, IntechOpen, Rijeka, 2020: p. Ch. 4. https://doi.org/10.5772/intechopen.89883.

[26] H. Michel, J. Behr, A. Harrenga, A. Kannt, Cytochrome c oxidase: Structure and spectroscopy, Annu. Rev. Biophys. Biomol. Struct. 27 ( 1998) 3356.

https://doi.org/10.1146/annurev.biophys.27.1.329.

[27] K.M. Kadish, Redox Tunning of Metalloporphyrin Reactivity, J. Electroanal. Chem. 108 ( 1984) 99Г4.

[28] J. Zagal, M. Páez, A.A. Tanaka, C.A. Linkous, Electrocatalytic reduction activity of metal phthalocyanines for oxygen reduction, J. Electroanal. Chem. 339 ( 1992) -BB.

[29] M. Yuasa, R. Nishihara, C. Shi, F.C. Anson, A Comparison of Several Meso -Tetraalkyl Cobalt Porphyrins as Catalysts for the Electroreduction of Dioxygen, Polym. Adv. Technol. 270 ( 2001) 2860 .

[30] E. Song, C. Shi, F.C. Anson, Comparison of the Behavior of Several Cobalt Porphyrins as Electrocatalysts for the Reduction of O2 at Graphite Electrodes, Langmuir. 7463 ( 1998) 4315-4321.

[31] D. Ozer, R. Harth, U. Mor, A. Bettelheim, Electrochemistry porphyrins of various substituted aminophenyl iron Part II . Catalytic reduction of dioxygen by electropolymerized films, J. Electroanal. Chem. 266 ( 1989) 1023. 
[32] A. Bettelheim, D. Ozer, R. Harth, Electrochemistry porphyrins of various substituted aminophenyl iron Part I . Redox properties of dissolved, adsorbed and electropolymerized species, J. Electroanal. Chem. 266 ( 1989) -9B38.

[33] J.H. Zagal, M.T.M. Koper, Reactivity Descriptors for the Activity of Molecular MN4 Catalysts for the Oxygen Reduction Reaction, Angew. Chemie Int. Ed. 55 ( 2016) 14510 14521.

[34] J.H. Zagal, S. Specchia, P. Atanassov, Mapping transition metal-MN4 macrocyclic complex catalysts performance for the critical reactivity descriptors, Curr. Opin. Electrochem. 27 ( 2021) 100683tps://doi.org/10.1016/j.coelec.2020.100683.

[35] S. Specchia, P. Atanassov, J.H. Zagal, Mapping transition metal-nitrogen-carbon catalyst performance on the critical descriptor diagram, Curr. Opin. Electrochem. 27 ( 2021) 100687. https://doi.org/10.1016/j.coelec.2021.100687.

[36] R. Venegas, K. Muñoz-Becerra, C. Candia-Onfray, J.F. Marco, J.H. Zagal, F.J. Recio, Experimental reactivity descriptors of M-N-C catalysts for the oxygen reduction reaction, Electrochim. Acta. 332 ( 2020) 135340.

[37] G. Abarca, M. Viera, C. Aliaga, J.F. Marco, W. Orellana, J.H. Zagal, F. Tasca, In search of the most active MN4 catalyst for the oxygen reduction reaction. The case of perfluorinated Fe phthalocyanine., J. Mater. Chem. A. 7 ( 2019) 247264783.

[38] J. Govan, G. Abarca, C. Aliaga, B. Sanhueza, W. Orellana, G. Cárdenas-Jirón, J.H. Zagal, F. Tasca, "Influence of cyano substituents on the electron density and catalytic activity towards the oxygen reduction reaction for iron phthalocyanine". The case for $\mathrm{Fe}$ ( II) 2,3,9,10,16,17,23,24-octa( cyano) phthalocyanine., Electrochem. Commun. ( 2020) In press.

[39] J.H. Zagal, S. Griveau, M. Santander-Nelli, S. Gutierrez, Carbon nanotubes and metalloporphyrins and metallo - phthalocyanines-based materials for electroanalysis, J. Porphyr. Phthalocyanines. 16 ( 2012) 71/340.

[40] I. Kruusenberg, L. Matisen, K. Tammeveski, Oxygen Electroreduction on Multi-Walled Carbon Nanotube Supported Metal Phthalocyanines and Porphyrins in Alkaline Media, J. Nanosci. Nanotechnol. 13 ( 2013) 62627.

[41] I. Kruusenberg, L. Matisen, K. Tammeveski, Oxygen Electroreduction on Multi-Walled Carbon Nanotube Supported Metal Phthalocyanines and Porphyrins in Acid Media, Int. J. Electrochem. Sci. 8 ( 2013) 1057066.

[42] Y. Peng, L. Li, Zhipan, Xia, Dingguo, Zheng, X. Liao, Yi, Li, Kai, Zuo, Probing the in fluence of the center atom coordination structure in iron phthalocyanine multi-walled carbon nanotube-based oxygen reduction reaction catalysts by X-ray absorption fi ne structure spectroscopy, J. Power Sources. 291 ( 2015) -228.

[43] J. Yang, J. Tao, T. Isomura, H. Yanagi, I. Moriguchi, N. Nakashima, A comparative study of iron phthalocyanine electrocatalysts supported on different nanocarbons for oxygen reduction reaction, Carbon N. Y. 145 ( 2019) 5651. 
[44] W. Visscher, J.A.R. Van Veen, On Active-Site Heterogeneity in Pyrolyzed CarbonSupported Iron Porphyrin Catalysts for the Electrochemical Reduction of Oxygen : An In Situ Mossbauer Study, J. Phys. Chem. B. 106 ( 2002) 12993001.

[45] G. Lalande, R. Coté, D. Guay, P. Bertrand, L.T. Weng, Is nitrogen important in the formulation of Fe-based catalysts for oxygen reduction in solid polymer fuel cells?, Electrochim. Acta. 42 ( 1997$) 1378888$.

[46] W. Visscher, J.A.R. Van Veen, The selectivity of oxygen reduction by pyrolysed iron porphyrin supported on carbon, Electrochim. Acta. 43 ( 1998) $31 \$ 1152$.

[47] J.P. Dodelet, M. Lefevre, P. Bertrand, Molecular Oxygen Reduction in PEM Fuel Cells : Evidence for the Simultaneous Presence of Two Active Sites in Fe-Based Catalysts, J. Phys. Chem. B. 106 ( 2002) $87(85713$.

[48] M. Lefevre, Fe-based catalysts for the reduction of oxygen in polymer electrolyte membrane fuel cell conditions : determination of the amount of peroxide released during electroreduction and its influence on the stability of the catalysts, Electrochim. Acta. 48 ( 2003) 274960.

[49] N. Kobayashi, W.A. Nevin, Electrocatalytic Reduction of Oxygen Using Water-soluble Iron and Cobalt Phthalocyanines and Porphyrins, Appl. Organomet. Chem. 10 ( 1996) $5 \overline{5} 90$.

[50] C. Zúñiga, C. Candia-Onfray, R. Venegas, K. Muñoz, J. Urra, M. Sánchez-Arenillas, J.F. Marco, J.H. Zagal, F.J. Recio, Elucidating the mechanism of the oxygen reduction reaction for pyrolyzed Fe-N-C catalysts in basic media, Electrochem. Commun. 102 ( 201$) 7882$. https://doi.org/10.1016/j.elecom.2019.04.005.

[51] R. Cao, R. Thapa, H. Kim, X. Xu, M. Gyu Kim, L.P. Qing, L. Noejung, C. Meilin, Promotion of oxygen reduction by a bio-inspired tethered iron phthalocyanine carbon nanotube-based catalyst., Nat. Commun. 4 ( 2013) 2076.

[52] R. Venegas, F.J. Recio, J. Riquelme, K. Neira, F. Marco, I. Ponce, H. Zagal, F. Tasca, Biomimetic reduction of $\mathrm{O}_{2}$ in an acid medium on iron phthalocyanines axially coordinated to pyridine anchored on carbon nanotubes, J. Mater. Chem. A. 5 ( 2017$) 12054059$.

[53] J. Riquelme, K. Neira, J.F. Marco, P. Hermosilla-Ibáñez, J.H. Zagal, F. Tasca, Biomimicking vitamin B12. A Co phthalocyanine pyridine axial ligand coordinated catalyst for the oxygen reduction reaction, Electrochim. Acta. 265 ( 2018) 5455.

[54] P. Wei, G. Yu, Y. Naruta, J. Liu, Covalent Grafting of Carbon Nanotubes with a Biomimetic Heme Model Compound To Enhance Oxygen Reduction Reactions, Angew. Chemie Int. Ed. 53 ( 2014) 665563.

[55] I. Ponce, J.F. Silva, R. Oñate, M. Caroli, M. Paez, J. Zagal, J. Pavez, F. Mendizabal, Enhancement of the Catalytic Activity of Fe Phthalocyanine for the Reduction of $\mathrm{O} 2$ Anchored to Au ( 111) via Conjugated Selssembled Monolayers of Aromatic Thiols As Compared to $\mathrm{Cu}$ Phthalocyanine, J. Phys. Chem. C. 116 ( 2012) 15325341.

[56] I. Ponce, J.F. Silva, R. Oñate, M. Caroli, M. Paez, J. Pavez, J.H. Zagal, Enhanced catalytic 
activity of Fe phthalocyanines linked to $\mathrm{Au}(111)$ via conjugated saksembled monolayers of aromatic thiols for $\mathrm{O}_{2}$ reduction, Electrochem. Commun. 13 ( 2011) 118285.

[57] I. Ponce, J.F. Silva, R Oñate, S. Miranda-Rojas, A. Muñoz, F. Mendizabal, H. Zagal, Theoretical and experimental study of bonding and optical properties of self-assembly metallophthalocyanines complexes on a gold surface. A survey of the substrate a surface interaction., J. Phys. Chem. C. ( 2011) 235-D2518.

[58] A. Pizarro, G. Abarca, C. Gutiérrez-Cerón, D. Cortés-Arriagada, F. Bernardi, C. Berrios, J.F. Silva, M.C. Rezende, J.H. Zagal, R. Onate, I. Ponce, Building Pyridinium Molecular Wires as Axial Ligands for Tuning the Electrocatalytic Activity of Iron Phthalocyanines for the Oxygen Reduction Reaction, ACS Catal. 8 ( 2018) 848419.

[59] C. Gutiérrez-Ceron, R. Oñate, J.H. Zagal, A. Pizarro, J.F. Silva, C. Castro-Castillo, M.C. Rezende, M. Flores, D. Cortés-Arriagada, A. Toro-Labbé, L.M. Campos, L. Venkataraman, I. Ponce, Molecular conductance versus inductive effects of axial ligands on the electrocatalytic activity of self-assembled iron phthalocyanines: The oxygen reduction reaction, Electrochim. Acta. 327 ( 2019) 134996. https://doi.org/10.1016/j.electacta.2019.134996.

[60] J.H. Zagal, I. Ponce, D. Baez, R. Venegas, J. Pavez, M. Paez, M. Gulppi, A Possible Interpretation for the High Catalytic Activity of Heat-Treated Non-Precious Metal Nx/C Catalysts for $\mathrm{O}_{2}$ Reduction in Terms of Their Formal Potentials, Electrochem. Solid-State Lett. 15 ( 2012) B90. https://doi.org/10.1149/2.032206esl.

[61] V. Briois, E. Fonda, S. Belin, L. Barthe, C. La Fontaine, F. Langlois, M. Ribbens, F. Villain, SAMBA: The 4-40 keV X-ray absorption spectroscopy beamline at SOLEIL, UVX 2010 10e Colloq. Sur Les Sources Cohérentes Incohérentes UV, VUV X; Appl. Développements Récents. ( 2011) -417.

[62] F. Neese, The ORCA program system, Wires Comput. Mol. Sci. 2 ( 2012) -7מB.

[63] F. Neese, Software update: the ORCA program system, version 4.0, Wires Comput. Mol. Sci. 8 ( 2018)-61

[64] J.P. Perdew, K. Burke, Y. Wang, Generalized gradient approximation for the exchangecorrelation hole of a many-electron system, Phys. Rev. B. 54 ( 1996) 53539.

[65] M. Casarin, M. Di Marino, D. Forrer, M. Sambi, F. Sedona, E. Tondello, A. Vittadini, V. Barone, M. Pavone, S. Chimiche, V. Uni, Coverage-Dependent Architectures of Iron Phthalocyanine on Ag ( 110) : a Comprehensive STM / DFT Study, J. Phys. Chem. C. 114 ( 2010) 214453.

[66] K. Wu, Q.-H. Huang, H.-J. Zhang, Q. Liao, P.-M. He, Adsorption behavior of iron phthalocyanine on a Adsorption behavior of iron phthalocyanine on a $\operatorname{Ag}(110)$ surface, Chinese Phys. B. 21 ( 2012) 037202.

[67] S. Grimme, S. Ehrlich, L. Goerigk, Effect of the Damping Function in Dispersion Corrected Density Functional Theory, J. Comput. Chem. 32 ( 2011) $145 \$ 65$. 
[68] A.D. Becke, E.R. Johnson, A density-functional model of the dispersion interaction, J. Chem. Phys. 123 ( 2005) 154101.

[69] S.F. Boys, F. Bernardi, The calculation of small molecular interactions by the differences of separate total energies. Some procedures with reduced errors, Mol. Phys. 19 ( 1970) 3 3fh.

[70] A. Becke, The Quantum Theory of Atoms in Molecules: From Solid State to DNA and Drug Design, John Wiley \& Sons, 2007.

[71] T. Lu, F. Chen, Multiwfn: A Multifunctional Wavefunction Analyzer, J. Comput. Chem. 33 ( 2012) 58902.

[72] R.Graupner, Raman spectroscopy of covalently functionalized single-wall carbon nanotubes, J. Raman Spectrosc. 38 ( 2007) 6783.

[73] M.K. Bayazit, L.S. Clarke, K.S. Coleman, N. Clarke, Pyridine-Functionalized Single-Walled Carbon Nanotubes as Gelators for Poly ( acrylic acid) difggels, J. Am. Chem. Soc. 132 ( 2010) 158115819.

[74] M.S. Strano, Electronic Structure Control of Single-Walled Carbon Nanotube Functionalization, Science. 301 ( 2003) 1511522.

[75] B.M. Biwer, S.L. Bernasek, Electron spectroscopic study of the iron surface and its interaction with oxygen and nitrogen, J. Electron Spectros. Relat. Phenomena. 40 ( 1986) $339-351$.

[76] G. Bhargava, I. Gouzman, C.M. Chun, T.A. Ramanarayanan, S.L. Bernasek, Characterization of the "native" surface thin film on pure polycrystalline iron: A high resolution XPS and TEM study, Appl. Surf. Sci. 253 ( 2007) 4322329.

[77] W. Huang, J.M. Ahl, P.A. Kohl, X. Zhang, Heat treated Tethered Iron Phthalocyanine Carbon Nanotube-based Catalysts for Oxygen Reduction Reaction in Hybrid Fuel Cells, Electrochim. Acta. 257 ( 2017) 2282.

[78] G. V. Ouedraogo, D. Benlian, L. Porte, X-ray photoelectron spectroscopy of phthalocyanine compounds, J. Chem. Phys. 73 ( 1980) 64247.

[79] R. Arrigo, M. Hävecker, R. Schlögl, D.S. Su, Dynamic surface rearrangement and thermal stability of nitrogen functional groups on carbon nanotubes., Chem. Commun. ( Camb) . ( 2008) 4891893.

[80] E.M.M. Ibrahim, V.O. Khavrus, A. Leonhardt, S.O. Hampel, M.H. Steffen Rümmeli, B. Büchner, Synthesis, characterization, and electrical properties of nitrogen-doped singlewalled carbon nanotubes with different nitrogen content, Diam. Relat. Mater. 19 ( 2010) 1199-1206.

[81] D. V. Konarev, A. V. Kuzmin, M. Ishikawa, Y. Nakano, M.A. Faraonov, S.S. Khasanov, A. Otsuka, H. Yamochi, G. Saito, R.N. Lyubovskaya, Layered Salts with Iron Hexadecachlorophthalocyanine Anions - The Formation of [\{FeCl16Pc $\} 2] 3-$ Dimers Containing [FeICl16Pc( 2) Jand Diamagnetic [Fe0Cl16Pc( 2) ]2, Eur. J. Inorg. Chem. 
2014 ( 2014) 386370.

[82] A. Zitolo, V. Goellner, V. Armel, M.T. Sougrati. T. Mineva, L. Stievano, E. Fonda, F. Jaouen, Identification of catalytic sites for oxygen reduction in iron- and nitrogen-doped graphene materials, Nat. Mater. ( 2015) 9972.

[83] S. Kim, T. Ohta, In situ Structural Investigation of Iron Phthalocyanine Monolayer Adsorbed on Electrode Surface by X-ray Absorption Fine Structure, Bull. Korean Chem. Soc. 21 ( 2000) 5884.

[84] C. Cartier, M. Momenteau, P.E. Dartyge, A. Fontaine, G. Tourillon, A. Michalowiczrc, M. Verdaguer, X-Ray Absorption Spectroscopy of Iron-( II) ar(d IIl) Basthetndle Porphyrins, J. Chem. Soc. Dalt. Trans. 4 ( 1992) 66998.

[85] C.E. Banks, R.R. Moore, T.J. Davies, R.G. Compton, Investigation of modified basal plane pyrolytic graphite electrodes : definitive evidence for the electrocatalytic properties of the ends of carbon nanotubes, Chem. Commun. 6 ( 2004) 1801805.

[86] F. Bedioui, S. Griveau, T. Nyokong, J. Appleby, C. Caro, M. Gulppi, G. Ochoa, J. Zagal, Tuning the redox properties of metalloporphyrin and metallophthalocyanine-based molecular electrodes for the highest electrocatalytic activity in the oxidation of thiols, Phys. Chem. Chem. Phys. 9 ( 2007) 338396.

[87] J. Masa, K. Ozoemena, W. Schuhmann, J.H. Zagal, Oxygen reduction reaction using N4metallomacrocyclic catalysts: fundamentals on rational catalyst design, J. Porphyr. Phthalocyanines. 16 ( 2012) 7684.

[88] J.H. Zagal, F. Javier Recio, C.A. Gutierrez, C. Zuñiga, M.A. Páez, C.A. Caro, Towards a unified way of comparing the electrocatalytic activity MN4 macrocyclic metal catalysts for $\mathrm{O}_{2}$ reduction on the basis of the reversible potential of the reaction, Electrochem. Commun. 41 ( 2014) -24 .

[89] J. Zagal, P. Bindra, E. Yeager, A Mechanistic Study of $\mathrm{O}_{2}$ Reduction on Water Soluble Phthalocyanines Adsorbed on Graphite Electrodes, J. Electrochem. Soc. 127 ( 1980) 1506 1517.

[90] A.J. Bard, L.R. Faulkner, Electrochemical Methods: Fundamentals and Applications, Wiley 2001. 